\title{
Intraglomerular Lateral Inhibition Promotes Spike Timing Variability in Principal Neurons of the Olfactory Bulb
}

\author{
Marion Najac, ${ }^{1,2}$ Alvaro Sanz Diez, ${ }^{3} \oplus^{\circledR}$ Arvind Kumar, ${ }^{4}$ Nuria Benito, ${ }^{3}$ Serge Charpak, ${ }^{1,2}$ and $\odot$ Didier De Saint Jan ${ }^{1,2,3}$ \\ ${ }^{1}$ Institut National de la Santé et de la Recherche Médicale Unité 1128, and ${ }^{2}$ Université Paris Descartes, 75006 Paris, France, ${ }^{3}$ Institut des Neurosciences \\ Cellulaires et Intégratives, Centre National de la Recherche Scientifique, Unité Propre de Recherche 3212, Université de Strasbourg, 67084 Strasbourg, \\ France, and ${ }^{4}$ Computational Biology, School of Computer Science and Communication, Royal Institute of Technology, Stockholm, SE-110 40, Sweden
}

The activity of mitral and tufted cells, the principal neurons of the olfactory bulb, is modulated by several classes of interneurons. Among them, diverse periglomerular (PG) cell types interact with the apical dendrites of mitral and tufted cells inside glomeruli at the first stage of olfactory processing. We used paired recording in olfactory bulb slices and two-photon targeted patch-clamp recording in vivo to characterize the properties and connections of a genetically identified population of PG cells expressing enhanced yellow fluorescent

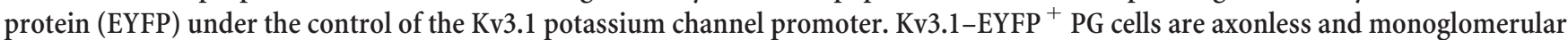
neurons that constitute $\sim 30 \%$ of all PG cells and include calbindin-expressing neurons. They respond to an olfactory nerve stimulation with a short barrage of excitatory inputs mediated by mitral, tufted, and external tufted cells, and, in turn, they indiscriminately release GABA onto principal neurons. They are activated by even the weakest olfactory nerve input or by the discharge of a single principal neuron in slices and at each respiration cycle in anesthetized mice. They participate in a fast-onset intraglomerular lateral inhibition between principal neurons from the same glomerulus, a circuit that reduces the firing rate and promotes spike timing variability in mitral cells. Recordings in other PG cell subtypes suggest that this pathway predominates in generating glomerular inhibition. Intraglomerular lateral inhibition may play a key role in olfactory processing by reducing the similarity of principal cells discharge in response to the same incoming input.

Key words: glomerulus; inhibition; olfactory bulb; periglomerular cell

\section{Introduction}

The olfactory bulb is the first station in the brain for odor processing (Shepherd, 2004). It receives sensory afferents from olfactory sensory neurons (OSNs) that bind odorants in the nasal epithelium. This information is transmitted to mitral and tufted cells, the principal output neurons of the bulb, within anatomical structures called glomeruli. Olfactory bulb networks modulate how mitral and tufted cells integrate and transform the spatiotemporal map of activated glomeruli into a temporal pattern of action potentials, i.e., the odor code that is ultimately decoded

Received May 29, 2014; revised Dec. 12, 2014; accepted Feb. 2, 2015

Author contributions:S.C. and D.d.S.J. designed research; M.N., A.S.D., N.B., and D.D.S.J. performed research;S.C. contributed unpublished reagents/analytic tools; M.N., A.S.D., A.K., and D.D.S.J. analyzed data; M.N. and D.D.S.J. wrote the paper.

This work was supported by the Leducq Foundation, Human Frontier Science Program Organisation Grant RGP0089/2009-C, National Agency for Research Grants ANR-12-JSV4-006-01 (D.D.S.J.) and ANR-R11036KK (S.C.), the Foundation for Medical Research, the National Institute of Health and Medical Research, the National Center of Scientific Research, and the Ministry of Higher Education and Research. We thank Thomas Knöpfel for the kind gift of the Kv3.1-EYFP transgenic mouse and Hannah Monyer for the kind gift of the CR-EGFP transgenic mouse. We also thank Gwenaëlle Bouchery and Andréa Virolle for technical assistance and members of the laboratory for constructive comments throughout the project.

Correspondence should be addressed to either of the following: Didier De Saint Jan, Institut des Neurosciences Cellulaires et Intégratives, Centre National de la Recherche Scientifique, Unité Propre de Recherche 3212, 5, rue Blaise Pascal, 67084 Strasbourg, France, E-mail: desaintjan@inci-cnrs.unistra.fr; or Serge Charpak, Laboratoire de Neurophysiologie et des Nouvelles Microscopies, Institut National de la Santé et de la Recherche Médicale, Unité 1128, 45, rue des Saints Pères, 75006 Paris, France. E-mail: serge.charpak@parisdescartes.fr.

DOI:10.1523/JNEUROSCI.2181-14.2015

Copyright $\odot 2015$ the authors $\quad 0270-6474 / 15 / 354319-13 \$ 15.00 / 0$ by downstream cortical neurons. However, the role of bulbar inhibitory circuits in shaping this temporal code is only partly understood.

Several types of interneurons interact with mitral and tufted cells. Granule and parvalbumin-positive $\left(\mathrm{PV}^{+}\right)$cells make reciprocal synapses with the lateral dendrites of mitral and tufted cells. Mitral and tufted cells activate these interneurons that in turn release GABA onto mitral and tufted cells (Isaacson and Strowbridge, 1998; Schoppa et al., 1998; Christie et al., 2001; Kato et al., 2013; Miyamichi et al., 2013). $\mathrm{PV}^{+}$cells mediate a broad and nonselective interglomerular lateral inhibition of widely distributed mitral and tufted cells, whereas granule cells inhibit fewer narrowly confined principal neurons projecting into specific glomeruli (Kato et al., 2013; Miyamichi et al., 2013). Models of olfactory bulb processing stress the importance of interglomerular lateral inhibition for sharpening odor tuning of principal neurons, enhancing contrast between glomerular units and facilitating odor discrimination (Yokoi et al., 1995; Mori et al., 1999; Abraham et al., 2010).

In contrast, little is known about the role of periglomerular (PG) interneurons that surround glomeruli and make synapses onto mitral and tufted cell intraglomerular dendrites (Pinching and Powell, 1971a; Toida et al., 1998; Kosaka and Kosaka, 2007). However, PG cells may provide as much as $50 \%$ of their inhibitory inputs (Dong et al., 2007), and recent evidence suggest that a stimulation of OSNs evokes a potent intraglomerular inhibition 
in mitral cells (Najac et al., 2011; Shao et al., 2012). However, PG cells constitute a diverse population of interneurons with different membrane properties (McQuiston and Katz, 2001; Hayar et al., 2004; Murphy et al., 2005; Shao et al., 2009), morphologies (Pinching and Powell, 1971b; Hayar et al., 2004; Kiyokage et al., 2010; Kosaka and Kosaka, 2010), and immunohistochemical properties (Kosaka and Kosaka, 2007; Panzanelli et al., 2007; Parrish-Aungst et al., 2007; Whitman and Greer, 2007), suggesting that each subtype may form circuits playing different functions.

Thus, to get a better insight into the function of intraglomerular inhibition, we investigated the properties and the synaptic circuits made by a specific subset of PG cells expressing enhanced yellow fluorescent protein (EYFP) under the control of the Kv3.1 potassium channel promoter (Metzger et al., 2002). We determined in vivo and in vitro, using targeted patch-clamp recording, the circumstances under which labeled PG cells are activated. Our results demonstrate that they generate a prominent intraglomerular lateral inhibition that is activated at each respiration cycle and modulates the frequency and precision of mitral and tufted cell discharges.

\section{Materials and Methods}

Slice preparation. Experimental protocols were approved by the National Institute of Health and Medical Research and the National Center of Scientific Research guidelines. Horizontal olfactory bulb slices were prepared from 14- to 30-d-old transgenic mice of either sex expressing the EYFP under the control of the $\mathrm{Kv} 3.1 \mathrm{~K}^{+}$channel promoter (Metzger et al., 2002) or the enhanced green fluorescent protein (EGFP) under the control of the calretinin (CR) promoter (Caputi et al., 2009). Note that, in these mice, the fluorescent protein expression may differ from the expression pattern of the Kv3.1 protein (Metzger et al., 2002) or the CR protein (Caputi et al., 2009). Mice were killed by decapitation, and the bulbs were dissected rapidly in ice-cold oxygenated $\left(95 \% \mathrm{O}_{2} / 5 \% \mathrm{CO}_{2}\right)$ solution containing the following (in $\mathrm{mm}$ ): $83 \mathrm{NaCl}, 26.2 \mathrm{NaHCO}_{3}, 1$ $\mathrm{NaH}_{2} \mathrm{PO}_{4}, 2.5 \mathrm{KCl}, 3.3 \mathrm{MgSO}_{4} 0.5 \mathrm{CaCl}_{2}, 70$ sucrose, and $22 \mathrm{D}$-glucose, pH 7.3 (osmolarity, $300 \mathrm{mOsm} / \mathrm{L}$ ). Slices $(300 \mu \mathrm{m}$ ) were cut using a Leica VT1000S or a Microm HM650V vibratome in the same solution, incubated for $30-40 \mathrm{~min}$ at $34^{\circ} \mathrm{C}$, and stored at room temperature in a regular artificial CSF (ACSF) until use. ACSF contained the following (in mu): $125 \mathrm{NaCl}, 25 \mathrm{NaHCO}_{3}, 2.5 \mathrm{KCl}, 1.25 \mathrm{NaH}_{2} \mathrm{PO}_{4}, 1 \mathrm{MgCl}_{2}, 2 \mathrm{CaCl}_{2}$, and 25 D-glucose (continuously bubbled with $95 \% \mathrm{O}_{2} / 5 \% \mathrm{CO}_{2}$ ).

Electrophysiological recordings in slices. Experiments were conducted at $32-34^{\circ} \mathrm{C}$ on an upright microscope (Olympus BX51WI) with differential interference contrast optics. Whole-cell voltage-clamp recordings of mitral, tufted, and external tufted (ET) cells were made with patch pipettes $(\sim 2-4 \mathrm{M} \Omega$ ) filled with an intracellular solution containing the following (in $\mathrm{mm}$ ): $120 \mathrm{Cs}-\mathrm{MeSO}_{3}, 20$ tetraethylammonium-Cl, 5 4-aminopyridine, $2 \mathrm{MgCl}_{2}, 0.025 \mathrm{CaCl}_{2}, 1 \mathrm{EGTA}, 4 \mathrm{Na}-\mathrm{ATP}, 0.5 \mathrm{Na}-\mathrm{GTP}$, and 10 HEPES, pH $7.3(\sim 280 \mathrm{Osm} / \mathrm{L}, \sim 10 \mathrm{mV}$ junction potential). Whole-cell current-clamp recordings were made with an internal solution containing the following (in $\mathrm{mM}$ ): $135 \mathrm{~K}$-gluconate, $2 \mathrm{MgCl}_{2}, 0.025 \mathrm{CaCl}_{2}, 1$ EGTA, 4 Na-ATP, $0.5 \mathrm{Na}$-GTP, and 10 HEPES, pH $7.3(\sim 280 \mathrm{Osm} / \mathrm{L}$, $\sim 15 \mathrm{mV}$ junction potential). PG cell recordings were all made with pipettes $(\sim 4-6 \mathrm{M} \Omega$ ) filled with the K-gluconate-based internal solution. We discriminated between tufted cells and ET cells as described previously (Najac et al., 2011). Alexa Fluor 594 (6 $\mu \mathrm{M}$; Invitrogen) was always added to the internal solution to confirm the glomerular projection of the recorded cell. For paired recording of synaptic transmission, the $\mathrm{K}$-gluconate-based internal solution in the presynaptic neuron was supplemented with $10 \mathrm{~mm}$ glutamate or $10 \mathrm{~mm}$ GABA to avoid transmitter depletion and the resulting rundown of the postsynaptic response. Loose cell-attached recordings (15-100 $\mathrm{M} \Omega$ seal resistance) were made with pipettes filled with ACSF and used several times on different neurons. Bundles of OSN axons projecting inside a given glomerulus were stimulated using a theta pipette filled with ACSF as described previously (Najac et al., 2011). The electrical stimulus $(100 \mu$ s) was delivered using an isolator-11 Stimulus Isolation Unit (Molecular Devices). Recordings were acquired with a multiclamp 700A amplifier (Molecular Devices), low-passed filtered at $2-4 \mathrm{kHz}$, and digitized at $10 \mathrm{kHz}$ using Clampex 9 software (Molecular Devices). In current-clamp recordings, a constant hyperpolarizing current was injected to maintain the cell at a potential of $-60 /-70 \mathrm{mV}$. In voltage-clamp recordings, access resistance $\left(R_{\mathrm{a}}<10\right.$ $\mathrm{M} \Omega$ for mitral, $R_{\mathrm{a}}<20 \mathrm{M} \Omega$ for tufted and ET cells, $R_{\mathrm{a}}<30 \mathrm{M} \Omega$ for PG cells) were not compensated. Voltages indicated throughout were corrected for the junction potential estimated with the Clampex software.

Drugs. 6-Nitro-7-sulfamoylbenzo[f]quinoxaline-2,3-dione (NBQX), D-2-amino-5-phosphonopentanoic acid (D-AP-5), 2-(3-carboxypropyl)-3-amino-6-(4 methoxyphenyl)pyridazinium bromide (GBZ), 7-(hydroxyimino)cyclopropa[b]chromen-1a-carboxylate ethyl ester (CPCCOEt), and 4-ethylphenylamino-1,2-dimethyl-6-methylaminopyrimidinium chloride (ZD7288) were purchased from Tocris Bioscience or Ascent Scientific.

Intraglomerular application of GBZ. Local intraglomerular applications of GBZ were made with a patch pipette filled with ACSF supplemented with GBZ. Alexa Fluor $594(10 \mu \mathrm{M})$ was also added to the pipette solution to monitor diffusion with fluorescence. Air pressure at the back of the pipette was applied either transiently (100-200 ms) using an electrical valve or continuously using a syringe.

PG cell morphology. To reconstruct the morphology of PG cells, biocytin (10 $\mathrm{mm}$ ) was added to the intracellular solution, and the patch pipette was slowly withdrawn immediately after breaking the membrane to avoid damaging the cell bodies. Slices were then fixed in $4 \%$ paraformaldehyde overnight, washed three times, and incubated in a permeabilizing solution containing Cy5-conjugated streptavidin ( $1 \mu \mathrm{g} / \mathrm{ml}$; Jackson ImmunoResearch) for $1 \mathrm{~d}$. After three wash cycles with PBS, sections were mounted. Labeled cells were imaged with a confocal microscope (Zeiss LSM 510).

Two-photon targeted patch-clamp recordings in vivo. Six- to 12-weekold Kv3.1-EYFP transgenic mice were anesthetized with an intraperitoneal injection of xylazine $(16 \mathrm{mg} / \mathrm{kg})$ and ketamine $(100 \mathrm{mg} / \mathrm{kg})$ and placed in a custom stereotaxic apparatus. The posterior cisterna was drained, and a small craniotomy was done on the dorsal side of one olfactory bulb. The dura was removed before stabilizing the bulb with agarose $(2 \% \mathrm{w} / \mathrm{v})$. After surgery, the animal was placed under a custombuilt two-photon laser scanning microscope (Charpak et al., 2001) equipped with a $40 \times$ water-immersion objective (numerical aperture, 0.8 ) and a Mira 900 mode-locked titanium:sapphire laser (Coherent). Anesthesia was switched to isoflurane $(1-2 \%, 3 \mathrm{~L} / \mathrm{min}$ in moisturized air $/ \mathrm{O}_{2}$ ), and its depth was monitored throughout by respiration rates along with lack of response to toe pinch. Body temperature was measured with a rectal probe (FHC) and maintained at $36-37^{\circ} \mathrm{C}$ with a heating pad (FHC). Respiration was monitored with a pressure pad (Biopac Systems) positioned under the chest. For recordings, we followed the two-photon targeted patching approach (Margrie et al., 2003) using regular patch pipettes $(\sim 4-8 \mathrm{M} \Omega)$ containing Alexa Fluor $594(10-20 \mu \mathrm{M})$. The dyefilled patch pipette and $\mathrm{EYFP}^{+}$neurons were imaged simultaneously with two detection channels using an excitation wavelength of $900 \mathrm{~nm}$. The pipettes were filled with (in $\mathrm{mm}$ ) $130 \mathrm{~K}$-gluconate, $4 \mathrm{MgCl}_{2}, 4 \mathrm{Na}$ ATP, $0.5 \mathrm{Na}$-GTP, 10 HEPES, and 10 phosphocreatinine, $\mathrm{pH} 7.3(\sim 280$ $\mathrm{Osm} / \mathrm{L}$ ) for the experiments shown in Figure $6 \mathrm{~A}$ or with the $\mathrm{Cs}-\mathrm{MeSO}_{3}$ based internal solution used in slices for the experiments shown in Figure 6B. Data were acquired the same way as in slices using an Axopatch 200B amplifier (Molecular Devices). Access resistances (25-40 M $\Omega$ ) were not compensated.

Analysis. Voltage-clamp data were digitally low-passed filtered offline at $1-2 \mathrm{kHz}$ when necessary and analyzed using Axograph X (Axograph Scientific) and Igor Pro (WaveMetrics). We measured the onset of EPSC and IPSCs at $5 \%$ of the first peak of the response. The latency of olfactory nerve (ON)-evoked EPSCs and IPSCs were defined as the time interval between the beginning of the stimulation artifact and the onset of the EPSC/IPSC. The latency of lateral inhibition in Figure 5 was defined as the time interval between the peak of the first action potential and the onset of the average IPSC. Trains of action potentials in the presynaptic cell were first aligned on the first spike of the train before computing the average IPSC. The jitter of EPSCs was defined as the SD of their latencies. 

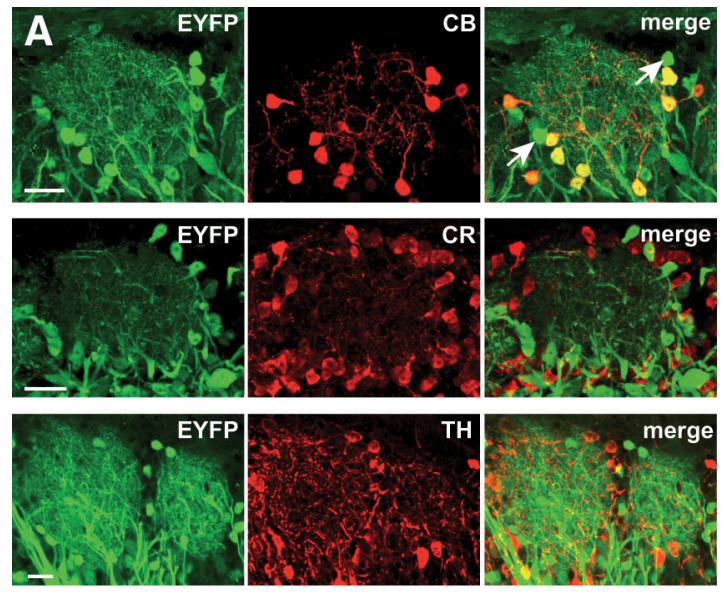

B
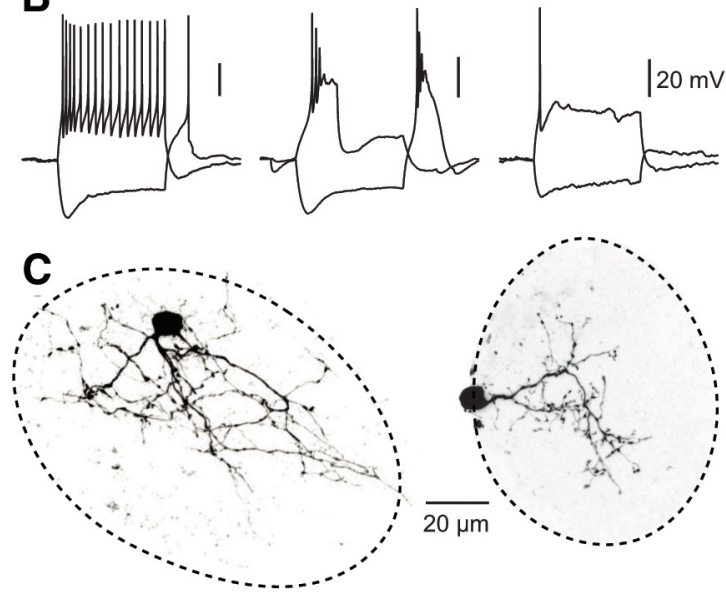

Figure 1. Characterization of EYFP ${ }^{+}$PG cells in Kv3.1-EYFP transgenic mice. $A$, Immunofluorescence staining for CB (top), CR (middle), and TH (bottom) in the glomerular layer of Kv3.1-EYFP transgenic mice. Note that all CB ${ }^{+}$PG cells express EYFP, but some EYFP ${ }^{+}$PG cells do not express CB (arrows). Scale bars, $20 \mu \mathrm{m}$. $\boldsymbol{B}$, Intrinsic membrane properties were diverse in EYFP ${ }^{+}$PG cells. Depolarizing and hyperpolarizing steps ( $500 \mathrm{~ms}$ ) were injected in EYFP ${ }^{+} \mathrm{PG}$ cells recorded in current-clamp at a membrane potential of approximately $-60 \mathrm{mV}$. The three examples show individual traces from three cells responding differently to a step depolarization. $\boldsymbol{C}$, Two biocytin-filled EYFP ${ }^{+}$PG cells. Dashed lines delimit the glomerulus into which each PG cell projected its dendrites. $\boldsymbol{D}$, Spontaneous EPSCs in an EYFP ${ }^{+}$PG cell recorded at $V_{\mathrm{h}}=-75 \mathrm{mV}$. Onset, Individual spontaneous EPSCs (black traces) and their average (white trace) are superimposed. $E$, Responses evoked by stimulation of OSNs (arrow) recorded in an EYFP ${ }^{+} \mathrm{PG}$ cell in the cell-attached (top) or whole-cell voltage-clamp mode at two intensities of stimulation indicated on the left (bottom; $V_{\mathrm{h}}=-75 \mathrm{mV}$ ). Individual traces are superimposed. Insets are zooms on the initial part of the response. Note that the latency and jitter of the responses decreased with the intensity of stimulation. The histogram plots the timing of individual EPSCs in responses evoked by the highest intensity of stimulation (bin width, 20 ms; stimulation at $t=0$ ).

Peristimulus time histograms (PSTHs) represent the average number of EPSCs (Fig. 1) or spikes (see Fig. 8) per bin during a sweep or during a respiration cycle (see Fig. 6). Spike timings were detected automatically with NeuroMatic (http://www.neuromatic.thinkrandom.com/) by a $y$-threshold level detector for values on a positive slope deflection. Reliability of mitral cell spiking responses (see Fig. 8) was analyzed using MATLAB (MathWorks). For the ensemble analysis of mitral cell responses to the stimulation of OSNs (see Fig. $8 G$ ), we constructed a nineneuron ensemble by pooling the nine recorded mitral cells, each of them having at least 14 trials for each condition, with and without GBZ. By random non-redundant combination of nine trials of $9 \times 14$, we created 14 artificial trials of the activity of an ensemble of nine mitral cells.

Unless indicated otherwise, we used the unpaired $t$ test to compare two sets of data acquired from different populations. Results are expressed as mean $\pm \mathrm{SD}$.

Immunohistochemistry. Adult mice (1-3 months old) were deeply anesthetized with an intraperitoneal injection of xylazine $(16 \mathrm{mg} / \mathrm{kg})$ and ketamine $(100 \mathrm{mg} / \mathrm{kg})$ and perfused with $4 \%$ paraformaldehyde in which the brains were kept overnight. Slices were cut with either a vibratome $(50 \mu \mathrm{m})$ or a cryostat $(20 \mu \mathrm{m})$. Before slicing with the cryostat, brains were cryoprotected and frozen. Blocking steps were performed by PBS solution containing $2 \%$ BSA and $0.1 \%$ Triton X-100. Sections were incubated $48 \mathrm{~h}$ at $4^{\circ} \mathrm{C}$ with primary antibodies: mouse monoclonal anti- calbindin D-28k (CB; 1:1000; Swant), rabbit anti-CR 7699/4 (1:1000; Swant), or rabbit polyclonal anti-tyrosine hydroxylase (TH; 1:500; Millipore). After washing, they were incubated $2 \mathrm{~h}$ at room temperature with secondary antibodies: Alexa Fluor 594-conjugated anti-mouse or antirabbit (1:300-1:500; Invitrogen). After washing, sections were mounted in Vectashield (Vector Laboratories). Confocal images were taken using a Zeiss LSM 510 confocal microscope, and cells were counted manually.

\section{Results}

Morphology, immunohistochemical identity, and membrane properties of a genetically identified PG cell subtype

In Kv3.1-EYFP transgenic mice, mitral and tufted cells, as well as a population of juxtaglomerular cells, express EYFP (Metzger et al., 2002). Using slices from juvenile olfactory bulb (15-30 postnatal days), we identified the EYFP ${ }^{+}$juxtaglomerular cells as PG cells (hereafter called EYFP ${ }^{+}$PG cells) on the basis of the small size of their round soma, their localization around glomeruli (Fig. 1A), and their large input resistance $(950 \pm 375 \mathrm{M} \Omega, n=$ $20)$. $\mathrm{EYFP}^{+}$PG cells filled with biocytin apparently had no axon $(n=11)$, and 10 of 11 projected their dendrites in a single glomerulus (Fig. 1C). PG cells have been classified anatomically into 
two broad classes (Kosaka and Kosaka, 2007): so-called type 1 PG cells are synaptically contacted by OSN axon terminals, whereas type 2 PG cells are not and receive excitatory inputs from the dendrites of mitral, tufted, or ET cells. Prototypical type 2 PG cells express the calcium binding proteins $\mathrm{CB}$ or CR (Kosaka and Kosaka, 2007). In Kv3.1-EYFP transgenic mice, virtually all PG cells immunoreactive for CB were EYFP ${ }^{+}$(388 of 392 cells, $n=5$ mice), but only half of $\mathrm{EYFP}^{+} \mathrm{PG}$ cells expressed CB (388 of 695 cells; Fig. $1 A)$. EYFP $^{+}$PG cells did not overlap with cells that express CR $(n=4$ mice; Fig. $1 A)$ nor with dopaminergic-GABAergic cells expressing $\mathrm{TH}$ ( $n=4$ mice; Fig. $1 A$ ). Thus, the population of EYFP ${ }^{+}$PG cells encompasses cells with different immunohistochemical properties. Because $\mathrm{CB}^{+}$ neurons constitute $14 \%$ of all PG cells (Panzanelli et al., 2007), we estimate that $\sim 30 \%$ of all PG cells are EYFP ${ }^{+}$in Kv3.1EYFP mice. Intrinsic membrane properties and firing patterns of EYFP ${ }^{+}$PG cells were also diverse (Fig. $1 B$ ). The majority of the cells responded to depolarizing current steps with large calcium spikes $(n=$ $16)$ and the others with sustained firing of sodium action potentials $(n=8)$ or with few sodium spikes preceding a plateau potential $(n=4)$. In most $(n=27$ of 28$)$ $\mathrm{EYFP}^{+} \mathrm{PG}$ cells, hyperpolarizing current steps caused a voltage sag. This rebound was blocked by ZD7288 $(50 \mu \mathrm{M})$, an antagonist of $I_{\mathrm{h}}$-mediating hyperpolarizationactivated cyclic nucleotide gated channels ( $n=7$ cells; data not shown).

\section{Synaptic properties of $\mathrm{EYFP}^{+}{ }^{+} \mathrm{PG}$ cells}

To characterize the synaptic properties of EYFP ${ }^{+}$PG cells, we first examined their spontaneous excitatory synaptic inputs and their responses to a brief (100 $\mu$ s) electrical stimulation of an OSN axon bundle converging into their glomerulus. Whole-cell voltage-clamp recordings of $\mathrm{EYFP}^{+} \mathrm{PG}$ cells $\left(V_{\mathrm{h}}=-75 \mathrm{mV}\right)$ revealed spontaneous EPSCs at a rate of $17.5 \pm 8.9$ per second $(n=24$; Fig. $1 D)$. The average EPSC had an amplitude of $50 \pm 23$ $\mathrm{pA}$ and a fast time course $(20-80 \%$ rise time, $0.28 \pm 0.05 \mathrm{~ms}$; decay time constant, $1.48 \pm 0.2 \mathrm{~ms})$. In the cell-attached configuration preceding whole-cell recordings, ON stimulation evoked a burst of few action potentials usually restricted to the first $50 \mathrm{~ms}$ after the stimulus $(3.7 \pm 1.4$ spikes, $94 \pm 6 \%$ within this temporal window, $n=14$; Fig. $1 E$ ). The first spike of the burst occurred with an average latency of $6.8 \pm 3.1 \mathrm{~ms}$ (range of 3-13.7 ms, $n=$ 14) that decreased with increasing stimulation intensity (data not shown). In the whole-cell configuration, ON stimulation evoked a brief barrage of fast summating EPSCs that summed up to $424 \pm 302 \mathrm{pA}(n=31)$ at strong intensities of stimulation (153 \pm $107 \mu \mathrm{A}$; Fig. $1 E$ ). To quantify the duration of these responses, we constructed PSTHs of EPSCs and fitted the decay of the histogram with an exponential. As in the example shown in Figure $1 E$, the majority of the cells ( $n=26$ of 31 ) had a response that quickly returned to baseline with a time constant $<100 \mathrm{~ms}$ (mean of $64 \pm$ $66 \mathrm{~ms}$; see Fig. $3 A$ ). At $V_{\mathrm{h}}=-75 \mathrm{mV}$, the AMPA receptor antag-
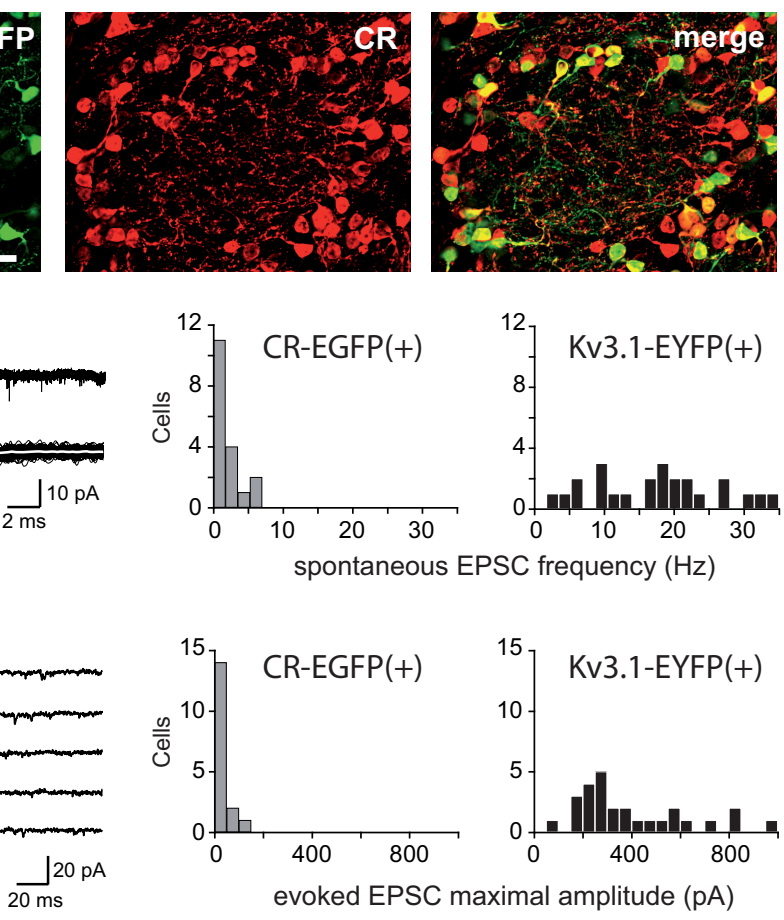

evoked EPSC maximal amplitude $(\mathrm{pA})$

Figure 2. A large fraction of $C R^{+} P G$ cells is weakly connected to the glomerular network. $A$, Immunofluorescence staining for CR (red, middle) revealed that only a fraction of $C R^{+} P G$ cells express EGFP (green, left) in CR-EGFP transgenic mice. Scale bar, 20

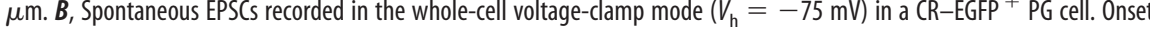
taneous EPSCs in CR-EGFP ${ }^{+}$PG cells (left) and Kv3.1-EYFP ${ }^{+}$PG cells (right). C, Five consecutive 0N-evoked whole-cell responses $\left(V_{\mathrm{h}}=-75 \mathrm{mV}\right)$ in a $\left(\mathrm{R}-\mathrm{EGFP}{ }^{+} \mathrm{PG}\right.$ cell. This stimulus $(200 \mu \mathrm{A}$, arrow) produced the largest responses. Distribution histograms compare the maximal amplitudes of $0 \mathrm{~N}$-evoked responses in CR-EGFP ${ }^{+} \mathrm{PG}$ cells (left) and Kv3.1-EYFP ${ }^{+}$PG cells (right).

onist NBQX $(10 \mu \mathrm{M})$ abolished evoked EPSCs $(n=3$; data not shown), whereas at $V_{\mathrm{h}}=30 \mathrm{mV}$, addition of the NMDA receptor antagonist d-AP-5 ( $50 \mu \mathrm{M})$ was required to block the EPSC $(n=$ 4; data not shown). As reported previously (Shao et al., 2009), the latency of the first EPSC and the jitter of the latency depended on the intensity of stimulation (Fig. $1 E)$. A strong stimulus $(110 \pm$ $101 \mu \mathrm{A}$ ) evoked an EPSC with an average latency of $3 \pm 0.7 \mathrm{~ms}$ and a jitter of $0.18 \pm 0.11 \mathrm{~ms}(n=17)$. With a weak stimulus $(36 \pm 14 \mu \mathrm{A})$, the average latency was $4.4 \pm 1.1 \mathrm{~ms}$ and the jitter was $0.6 \pm 0.5 \mathrm{~ms}(n=17)$. However, the latencies and jitters of responses evoked by stronger intensities were significantly larger than those of monosynaptically connected ET cells (latency, $2.0 \pm 0.4 \mathrm{~ms}, p<0.0001$; jitter, $0.07 \pm 0.06 \mathrm{~ms}, p=0.0007 ; n=$ 12 ET cells; data not shown) and those of PG cells type 1 (see Fig. $3 B$ ) and were consistent with a polysynaptic activation.

\section{PG cell functional diversity}

To evaluate the functional relevance of $\mathrm{EYFP}^{+} \mathrm{PG}$ cells, we compared their ON-evoked activation patterns with those of other PG cell subtypes. PG cells expressing CR are three times more numerous than CB-expressing PG cells and constitute the most abundant immunohistochemical subtype (Panzanelli et al., 2007; Parrish-Aungst et al., 2007; Whitman and Greer, 2007). We used transgenic mice expressing EGFP under the control of the CR promoter to identify these PG cells (Caputi et al., 2009). In CREGFP mice, only $56 \%$ of the cells immunoreactive for CR were also $\mathrm{EGFP}^{+}$(1173 of 2098 cells), but almost all EGFP ${ }^{+}$PG cells were immunoreactive for CR ( 1173 of 1185 cells, $n=6$ mice; Fig. $2 A)$. In the whole-cell configuration, CR-EGFP ${ }^{+} \mathrm{PG}$ cells had a high input resistance $(2 \pm 1.3 \mathrm{G} \Omega, n=30)$ and received significantly less spontaneous EPSCs $(1.8 \pm 1.9$ per second, $n=18)$ 
A

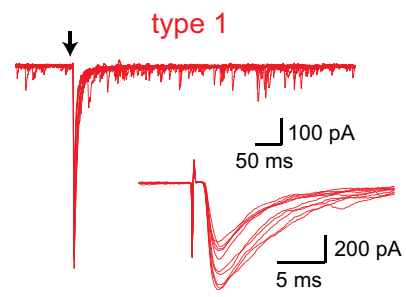

B

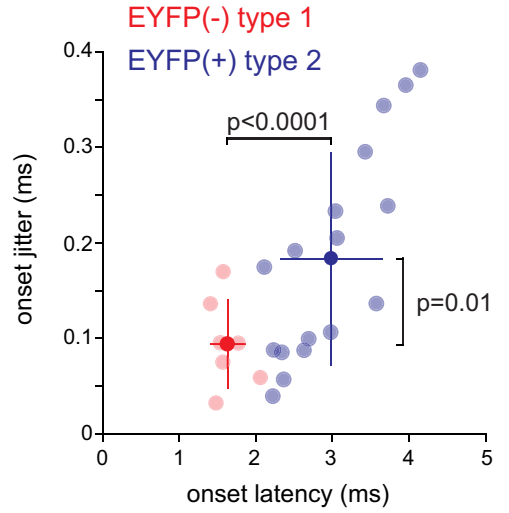

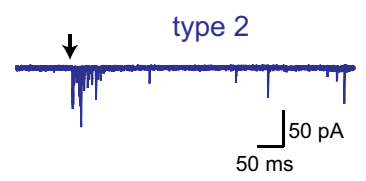
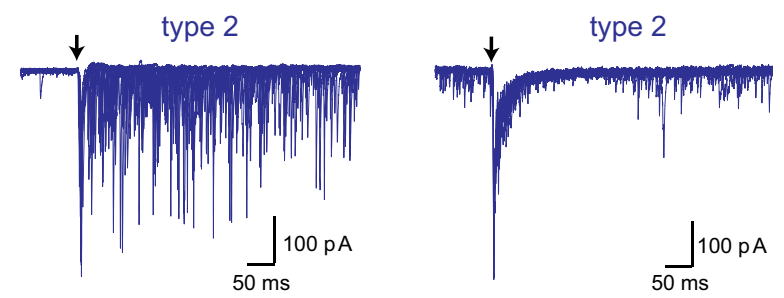

C
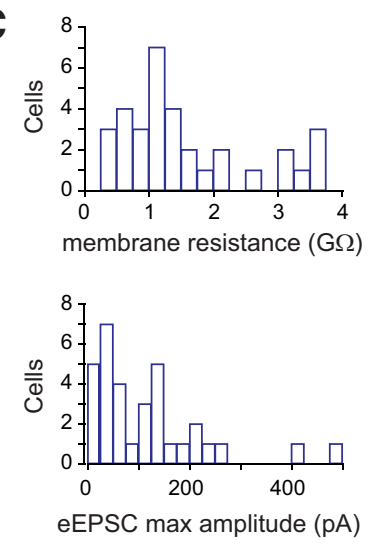

D

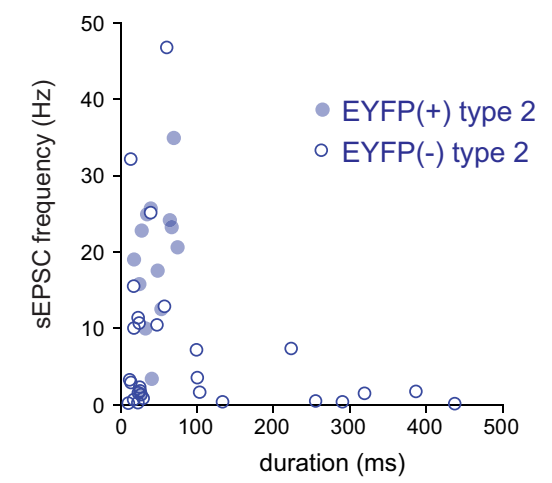

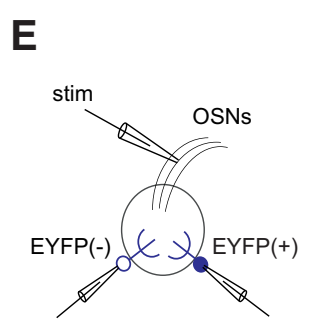

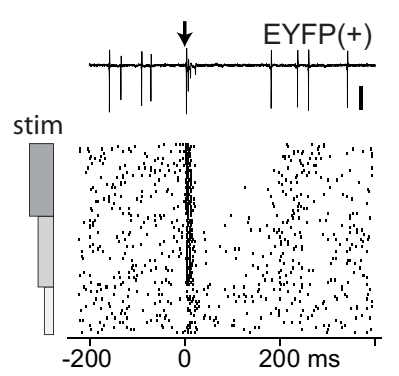

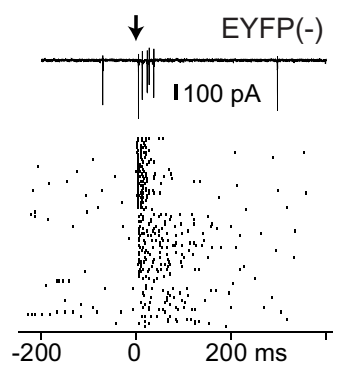

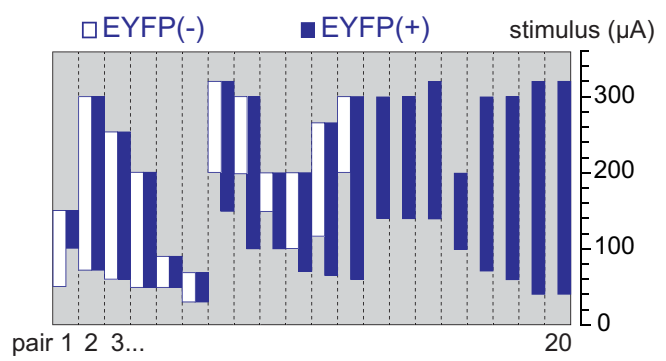

Figure 3. PG cell functional diversity. $A, 0$ N stimulation (arrow) evoked different types of responses in EYFP - PG cells. Type $1 P G$ cells (red traces) responded with a fast-onset monosynaptic EPSC (the inset is a zoom on the initial part of the response), whereas type $2 \mathrm{PG}$ cells responded with plurisynaptic responses of variable amplitudes and durations (3 examples shown with blue traces). $V_{\mathrm{h}}=-75 \mathrm{mV}$. In each case, several traces are superimposed. $\boldsymbol{B}$, The onset latency versus onset jitter of individual ON-evoked responses is plotted for EYFP ${ }^{+}$PG cells (blue circles) and EYFP ${ }^{-}$type 1 PG cells (red circles). Dark symbols and bars show the mean \pm SD. Strong intensities of stimulation were used here (110 $\pm 101 \mu A$ for EYFP ${ }^{+}$PGs and $239 \pm 122 \mu A$ for EYFP - PGs). $C$, Distribution histograms of the membrane resistance (top) and maximal amplitude of ON-evoked responses (eEPSC; bottom) in EYFP- type 2 PG cells ( $n=33$ ). $D$, The duration of the 0N-evoked response is plotted against the frequency of spontaneous EPSCs for each individual EYFP ${ }^{-}$type 2 PG cells (white circles). Values for EYFP ${ }^{+}$PG cells (blue circles) are also plotted for comparison. Durations were estimated from the fit of the latency histogram of each cell. $\boldsymbol{E}$, Comparison of ON-evoked firing in EYFP ${ }^{+}$and EYFP ${ }^{-}$PG cells. Action potentials were monitored using paired loose cell-attached recordings (scheme). Middle, Example of a pair that responded to $0 \mathrm{~N}$ stimulation with a similar threshold but different time course. One representative trace (top) and raster plots of 80 consecutive episodes (bottom) are shown. Each point indicates a spike. OSNs were stimulated (arrow) with increasing intensities. Right, Summary graph of the experiment. Each column shows a pair. White and blue vertical bars show the range of stimulus intensities that evoked the firing of the EYFP ${ }^{-}$and EYFP ${ }^{+}$PG cells, respectively. Columns with no white bars (pairs $13-20$ ) indicate pairs in which the EYFP - PG cells did not respond to the stimuli tested.

than $\mathrm{EYFP}^{+}$PG cells in the Kv3.1-EYFP mouse $(p<0.0001$; Fig. $2 B)$. Their average spontaneous EPSC was fast $(20-80 \%$ rise time, $0.29 \pm 0.08 \mathrm{~ms}$; decay, $1.5 \pm 0.5 \mathrm{~ms}$ ) but of smaller amplitude than in $\mathrm{EYFP}^{+}$PG cells $(13.9 \pm 6.3 \mathrm{pA}, p<0.0001)$. ON stimulation evoked a barrage of EPSCs that summed up to $33 \pm$ $34 \mathrm{pA}(n=17)$ at maximal intensities of stimulation $(320 \mu \mathrm{A})$, a much smaller amplitude than responses evoked in $\mathrm{EYFP}^{+} \mathrm{PG}$ cells $(p<0.0001$; Fig. $2 C)$. Small inputs could be sufficient to trigger the firing of a neuron with a high membrane resistance. However, most CR-EGFP ${ }^{+}$PG cells did not fire any action potentials spontaneously or in response to $\mathrm{ON}$ stimulation in the cell-attached (four of six silent cells) or loose cell-attached (six of eight silent cells) configuration. In the remaining four CR$\mathrm{EGFP}^{+}$cells, the stimulation evoked only one spike (data not shown). Similarly, in paired recording in the loose cell-attached mode of a CR-EGFP ${ }^{+}$and a CR-EGFP-negative $\left(\mathrm{CR}-\mathrm{EGFP}^{-}\right.$)
PG cell surrounding the same glomerulus, ON stimulation (50$200 \mu \mathrm{A}$ ) that induced the firing of the nonlabeled PG cell failed to activate the CR-EGFP ${ }^{+} \mathrm{PG}$ cell (in 9 of 11 pairs) or at most elicited a single spike ( $n=2$ of 11 pairs; data not shown). Thus, a large and previously undescribed fraction of $\mathrm{CR}^{+} \mathrm{PG}$ cells receives little excitatory inputs from the glomerular network and is not, or only weakly, activated by $\mathrm{ON}$ inputs that potently activate other PG cell subtypes.

To further explore PG cell diversity, we next examined ONevoked whole-cell voltage-clamp excitatory responses of randomly chosen nonfluorescent PG cells in Kv3.1-EYFP mice. We identified $17.5 \%$ of type 1 PG cells ( $n=7$ of 40 ; Fig. $3 A$ ) that responded with a fast-onset monosynaptic EPSC whose latency $(1.64 \pm 0.22 \mathrm{~ms})$ and jitter $(0.09 \pm 0.05 \mathrm{~ms})$ were significantly smaller than those of EYFP ${ }^{+} \mathrm{PG}$ cells (Fig. $3 B$ ). The other EYFP ${ }^{-}$ PG cells $(n=33)$ responded with a plurisynaptic barrage of EP- 
SCs of variable duration and amplitude. As expected, a large fraction of these type 2 PG cells $(n=13)$ had properties consistent with those of CR-EGFP ${ }^{+}$PG cells: a high membrane resistance $(>1.5 \mathrm{G} \Omega)$, small ON-evoked responses $(<100 \mathrm{pA})$ at maximal stimulation intensities, and a low frequency of spontaneous EPSCs $(<2$ $\mathrm{Hz}$; Fig. $3 A, C)$. The remaining EYFP ${ }^{-}$ type 2 PG cells $(n=20)$ responded either with a long-lasting barrage of EPSCs that could last several hundred milliseconds ( 11 cells with ON-evoked responses $>100$ $\mathrm{ms}$ ) or with a short plurisynaptic response indistinguishable from those of EYFP ${ }^{+}$ PG cells (Fig. 3A). Cells with long-lasting responses usually received a lower frequency of spontaneous EPSCs than cells with short responses (Fig. 3D). These different types of responses were neither glomerulus specific nor dependent on the stimulation strength because they were also observed in paired recordings between cells projecting into the same glomerulus ( $n=9$; data not shown). Therefore, they rather reflect specific synaptic connectivity and possibly distinguish functionally distinct subtypes.

In a third set of experiments in Kv3.1EYFP mice, we made paired recordings in the loose cell-attached mode of an EYFP ${ }^{+}$ and an $\mathrm{EYFP}^{-}$PG cell surrounding the same glomerulus and stimulated OSNs with increasing intensities until threshold $(n=20$ pairs; Fig. $3 E)$. Seventy percent of EYFP $^{-}$PG cells were not activated by weak stimuli that drive $\mathrm{EYFP}^{+} \mathrm{PG}$ cells.

Among these, $40 \%$ could not be activated at any intensities of stimulation, and 30\% had a higher firing threshold than EYFP ${ }^{+}$ PG cells. Most nonresponding cells were totally silent (five of eight), such as CR-EGFP ${ }^{+} \mathrm{PG}$ cells. The remaining $25 \%$ of EYFP $^{-}$PG cells ( 5 of 20) had a threshold that was approximately similar to $\mathrm{EYFP}^{+}$PG cells. Last, only one EYFP ${ }^{-}$PG cell $(5 \%)$ had a lower threshold than its paired EYFP ${ }^{+}$PG cell. Figure $3 E$ (middle) illustrates one pair of PG cells with a similar threshold but different firing patterns: the $\mathrm{EYFP}^{+} \mathrm{PG}$ cell responded as usual with a brief burst of action potentials, followed by a pause during which the EYFP ${ }^{-}$PG cell continued to fire. Thus, although $\mathrm{EYFP}^{+} \mathrm{PG}$ cells are not the only PG cell subtype activated by weak $\mathrm{ON}$ inputs, they form a large group of neurons with similar synaptic connections that likely plays a dominant role in generating intraglomerular inhibition in response to weak OSN inputs.

\section{Synaptic circuits formed by EYFP ${ }^{+}$PG cells}

We used paired recordings to identify the presynaptic partners of EYFP $^{+}$PG cells. Three glutamatergic cell types with glomerular projections - mitral, tufted, and ET cells - might provide excitatory inputs onto $\mathrm{EYFP}^{+} \mathrm{PG}$ cells. Contrasting with the idea that type $2 \mathrm{PG}$ cells receive their excitatory input principally from ET cells (Shao et al., 2009), we found that action potentials evoked in any of these glutamatergic neurons produced fast EPSCs in EYFP $^{+}$PG cells (Fig. 4). EPSC amplitudes varied between pairs
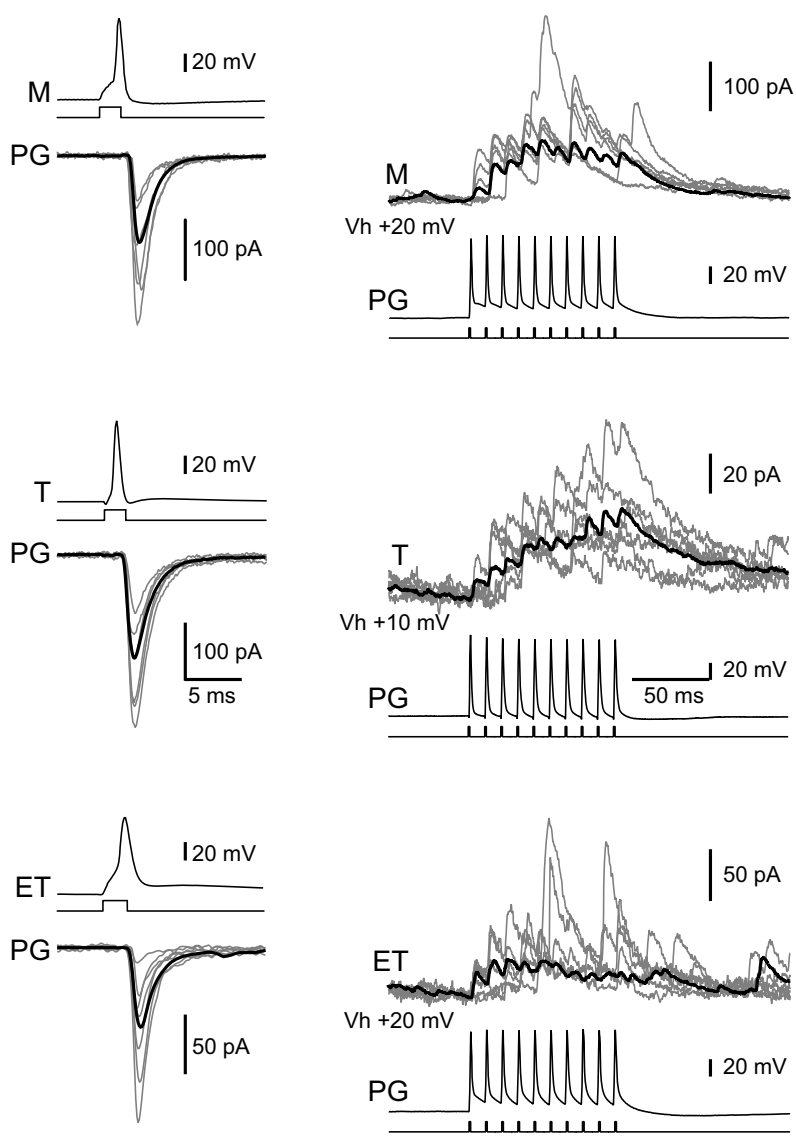

Figure 4. Synaptic connections of EYFP ${ }^{+} P G$ cells. $A$, Paired recordings between mitral (M) and EYFP ${ }^{+} P G$ cells. Left, Single action potentials evoked in the mitral cell produced fast EPSCs in the PG cell recorded at $V_{\mathrm{h}}=-70 \mathrm{mV}$. Six representative EPSCS potentials evoked in the $P G$ cell produced a barrage of ISPCs in the mitral cell recorded at $V_{h}=20 \mathrm{mV}$. Six sweeps are superimposed and the average from all trials appears in black. $\boldsymbol{B}$, Same for connected pairs of tufted (T) and EYFP ${ }^{+}$PG cells. C, Same for connected pairs of ET and EYFP ${ }^{+}$PG cells. IPSCs in $\boldsymbol{A}$ and $\boldsymbol{B}$ were recorded in the presence of NBQX $(10 \mu \mathrm{M})$ and D-AP-5 $(50 \mu \mathrm{m}) ; \boldsymbol{C}$ in ACSF.

and from trials to trials within pairs. On average, the EPSC amplitude was $140 \pm 222 \mathrm{pA}$ in ET-PG pairs $(n=15), 124 \pm 57 \mathrm{pA}$ in mitral-PG pairs $(n=6)$, and $160 \pm 122 \mathrm{pA}$ in tufted-PG pairs $(n=5)$ at $V_{\mathrm{h}}=-75 \mathrm{mV}$. In different pairs with mitral/tufted cells filled with a $\mathrm{Cs}^{2+}$-based internal solution and voltage clamped around the reversal potential for excitation $\left(V_{\mathrm{h}}=0 / 20\right.$ $\mathrm{mV}), 100 \mathrm{~Hz}$ trains of action potentials in the EYFP ${ }^{+}$PG cell produced a barrage of summating IPSCs in mitral $(n=2$ pairs; Fig. $4 A$ ), tufted ( $n=4$; Fig. $4 B)$, and ET ( $n=3$; Fig. $4 C)$ cells. These IPSCs persisted in the presence of NBQX and D-AP-5 $(n=$ $7)$ and were blocked by bath application of GBZ $(2 \mu \mathrm{M}, n=5$; data not shown). In most pairs (eight of nine), failures of GABAergic transmission were frequent after the first action potential $\left(64 \pm 18 \%\right.$ of failure). Thus, $\mathrm{EYFP}^{+} \mathrm{PG}$ cells are activated by mitral, tufted, and ET cells and in turn release GABA with a low probability onto mitral, tufted, and ET cells.

\section{Intraglomerular lateral inhibition between principal cells projecting into the same glomerulus}

We predicted that synaptic circuits made by EYFP ${ }^{+}$PG cells may generate lateral inhibition between principal neurons projecting into the same glomerulus (Urban and Sakmann, 2002). Thus, we tested whether principal cells with apical dendrites in the same glomerulus inhibit each other. In pairs of mitral cells, trains of action potentials were evoked in the first cell (Fig. 5, M1), whereas the postsynaptic response of the second cell (M2) was recorded in 
A
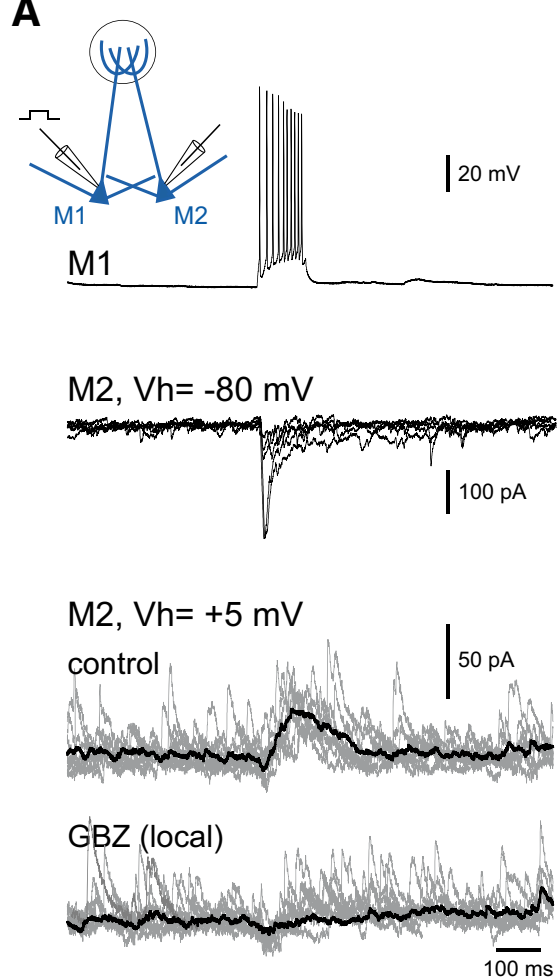

B
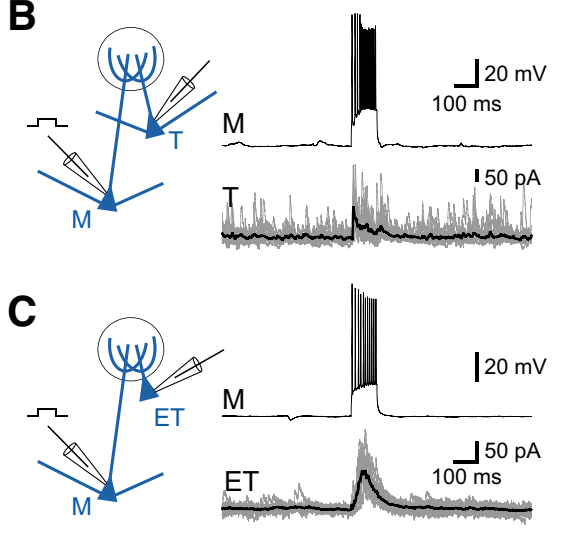

D

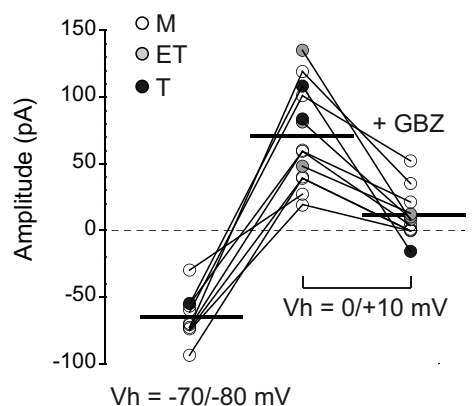

E
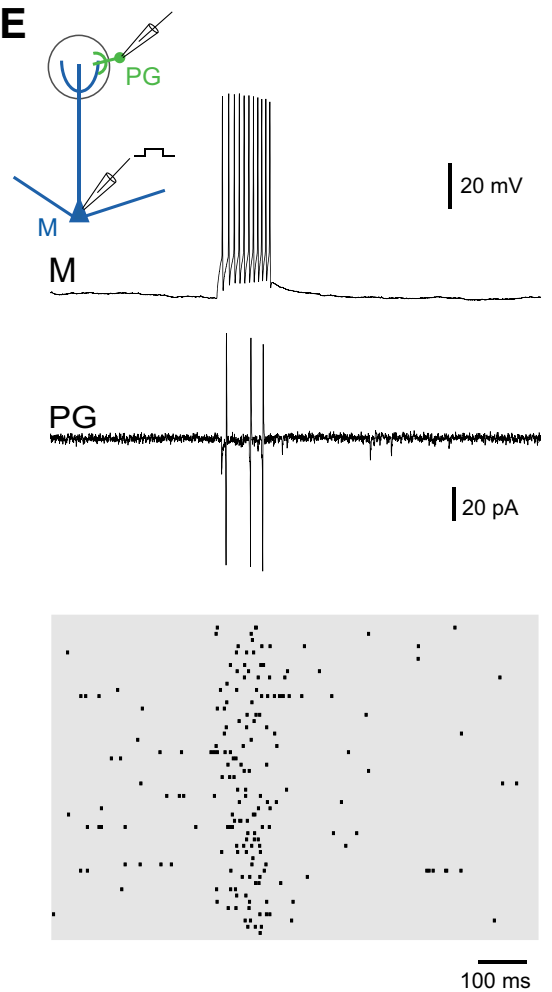

Figure 5. $\quad \mathrm{EYFP}^{+} \mathrm{PG}$ cells mediate lateral inhibition between mitral, tufted, and ET cells projecting into the same glomerulus. $A$, Paired recording between two mitral cells (M1 and M2) projecting into the same glomerulus. A current step (700 pA, $100 \mathrm{~ms})$ was used to evoke a train of action potentials in M1 (top trace) while simultaneously monitoring voltage-clamped responses in $\mathrm{M} 2$ (scheme). Inward EPSCs were recorded at $V_{\mathrm{h}}=-80 \mathrm{mV}$ (top traces, 5 traces superimposed). Outward IPSCs were recorded at $V_{\mathrm{h}}=5 \mathrm{mV}$ (bottom gray traces) in control conditions and after a transient puff of $\mathrm{GBZ}(50 \mu \mathrm{m}, 100 \mathrm{~ms}$ ) within the glomerulus. This protocol was repeated eight times. Traces before (control) and after (GBZ) the puff are superimposed. Average traces are shown in black. B, Same experiment in a pair of mitral (M) cell-tufted (T) cell. C, Same experiment in a pair of mitral (M) cell-ET cell. Experiments in A-Cin the presence of D-AP-5 (50 $\mu \mathrm{M})$ and CPCCOEt (100 $\mu \mathrm{M})$. D, Summary plot showing the amplitudes of the averaged postsynaptic current obtained at negative potentials $\left(V_{\mathrm{h}}=-70 /-80 \mathrm{mV}\right)$ and at a potential near $0 \mathrm{mV}$, under control conditions and in the presence of GBZ. Each plot is a mitral (white), tufted (black), or ET (gray) cell. Horizontal lines show the means. E, Paired recording between a mitral cell (M) recorded in the whole-cell mode and an EYFP ${ }^{+} \mathrm{PG}$ cell recorded in the loose cell-attached mode (PG). Both neurons projected into the same glomerulus. A train of action potentials induced by a current step (400 pA, $100 \mathrm{~ms}$ ) in the mitral cell (top trace) produced the firing of the PG cell (middle trace). Bottom, Raster plots of spontaneous and evoked action potentials in the PG cell.

voltage-clamp. These experiments were done in the presence of mGlu1 and NMDA receptor antagonists (CPCCOEt and D-AP-5, respectively) (1) to reduce the excitability of the network and spontaneous synaptic activity and (2) to limit the activation of granule cells. Fast synaptic inward currents were evoked when the postsynaptic cell was recorded at $V_{\mathrm{h}}=-70 /-80 \mathrm{mV}$ (Fig. $5 A, D)$, consistent with the existence of excitatory synaptic interactions and gap junction coupling between principal neurons affiliated with the same glomerulus (Schoppa and Westbrook, 2002; Urban and Sakmann, 2002). When the postsynaptic mitral cell was voltage clamped around the reversal potential for excitation $\left(V_{\mathrm{h}}=0 / 10 \mathrm{mV}\right)$, a burst of synaptic outward currents was evoked. The average outward current started $20 \pm 17 \mathrm{~ms}$ (range of 3-50 ms) after the first spike of the presynaptic mitral cell, had an amplitude of $58 \pm 35 \mathrm{pA}(n=8$; Fig. $5 D)$, and was blocked by a transient puff $(n=3,100 \mathrm{~ms}, 50 \mu \mathrm{M})$ or by a local perfusion of GBZ $(n=2,25 \mu \mathrm{M})$ inside the glomerulus (Fig. $5 A, D)$. Importantly, spontaneous IPSCs persisted during intraglomerular application of GBZ, indicating that the spread of GBZ outside the glomerulus was spatially limited (see Fig. 7). Firing of a single mitral cell also evoked a barrage of polysynaptic IPSCs in tufted cells ( $n=2$ pairs; amplitude, 83 and $108 \mathrm{pA}$; onset, 4.3 and 2.9 ms; Fig. $5 B$ ) and ET cells (amplitude, $68 \pm 49$ pA; onset, $20.7 \pm 35$ ms; range of $2.8-74 \mathrm{~ms} ; n=4$ pairs; Fig. $5 C$ ). The polysynaptic inhibition of ET cells is likely generated by intraglomerular circuits because ET cells, that lack lateral dendrites in the external plexiform layer (EPL), presumably do not interact with granule cells or $\mathrm{PV}^{+}$interneurons. Thus, our data suggest that glomerular circuits mediate lateral inhibition between principal neurons projecting into the same glomerulus. Do EYFP ${ }^{+} \mathrm{PG}$ cells participate in this form of lateral inhibition? If so, they should be activated by the firing of a single mitral cell. We tested this hypothesis in pairs of mitral and EYFP ${ }^{+} \mathrm{PG}_{\text {cells projecting into the same }}$ glomerulus. Trains of action potentials in a mitral cell evoked $1.8 \pm 0.9$ action potentials in an $\mathrm{EYFP}^{+} \mathrm{PG}$ cell recorded simultaneously in the loose cell-attached configuration in control conditions ( $n=4$ pairs; Fig. $5 E$ ), as well as in the presence of D-AP-5 ( $n=3$; data not shown). Thus, $\mathrm{EYFP}^{+} \mathrm{PG}$ cells participate to the circuit mediating intraglomerular lateral inhibition.

\section{Intraglomerular lateral inhibition is highly active in vivo}

The time course of olfactory processing is constrained by the 2-10 Hz respiratory rhythm. We used two-photon guided targeted patch-clamp recording in freely breathing anesthetized mice to examine the activity of $\mathrm{EYFP}^{+} \mathrm{PG}$ cells in vivo. Each recorded EYFP ${ }^{+}$PG cells exhibited rhythmic bursts of fast EPSCs $(n=9)$, consistent with mitral or tufted cell excitatory inputs. These bursts were correlated with the respiration cycle in eight of nine cells as in the example shown in Figure 6A. Moreover, EYFP $^{+} \mathrm{PG}$ recorded in cell-attached mode before breaking the membrane also fired bursts of action potentials at a specific phase of the respiration cycle ( $n=5$ of 5 cells; Fig. $6 A$ ). These results 
A

PG cell

cell-attached

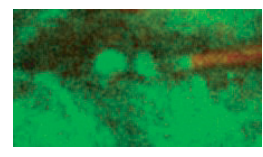

whole-cell

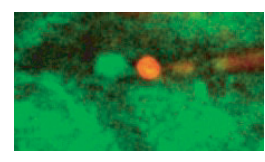

B

\section{Tufted cell}

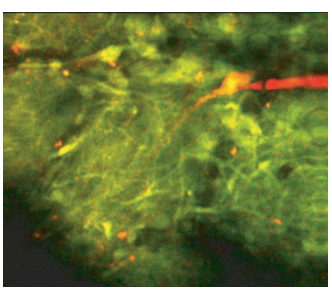

spontaneous firing

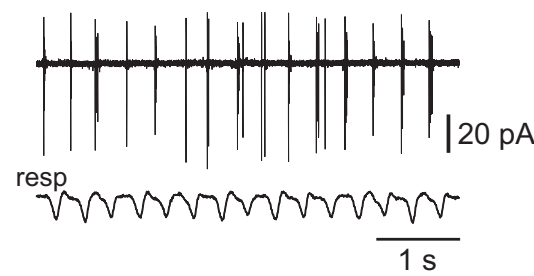

EPSC, Vh=-70 mV

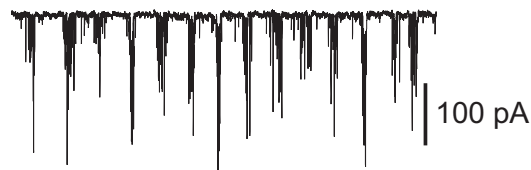

morroververs

IPSC, $\mathrm{Vh}=0 \mathrm{mV}$

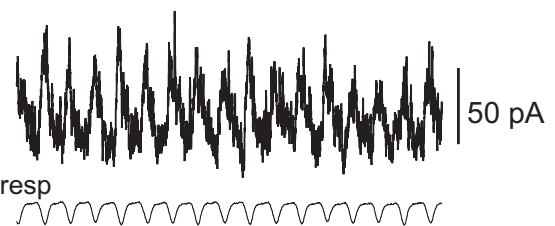

EPSC, $\mathrm{Vh}=-80 \mathrm{mV}$

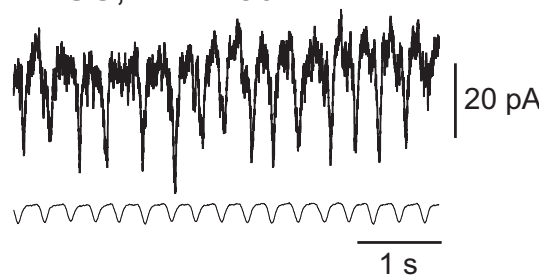

spike distribution

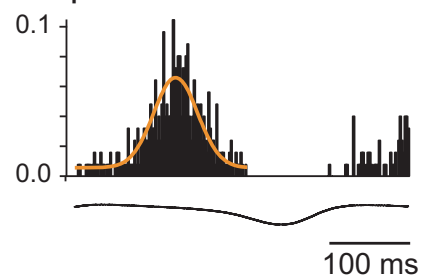

50 consecutive cycles

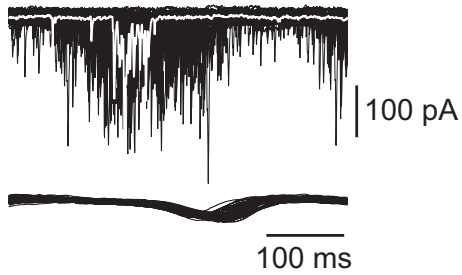

50 consecutive cycles
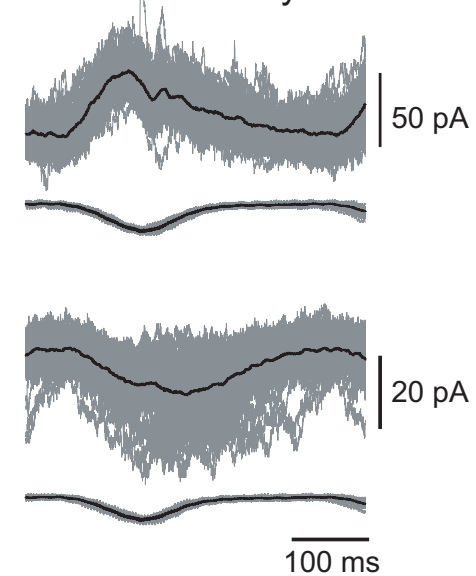

Figure 6. Activity of EYFP ${ }^{+} \mathrm{PG}$ cells in anesthetized mice. A, Picture of an EYFP ${ }^{+} \mathrm{PG}$ cell first recorded in the cell-attached mode (top) and then filled with Alexa Fluor 594 (red) during whole-cell recording (bottom). The spontaneous firing from this cell (top trace) was recorded in the cell-attached configuration before breaking the membrane. The corresponding respiration cycle is shown below the trace (upward deflection corresponds to inhalation). Respiration cycles were aligned, and PSTHs per respiration cycle were constructed (right). Bin width, $2 \mathrm{~ms}$. The orange trace is the best Gaussian fit of the histogram. The average respiration cycle waveform is shown below the PSTH. Bottom, Spontaneous EPSCs recorded in the whole-cell voltage-clamp configuration. Right, Thirty consecutive respiration cycles are superimposed, as are their corresponding whole-cell recordings. The white trace is a typical event. $\boldsymbol{B}$, Competing EPSCs and IPSCs underlie the spontaneous rhythmic activity of tufted cells in vivo. Left, Two-photon image of an EYFP ${ }^{+}$tufted cell during whole-cell recording in vivo. The patch pipette containing Alexa Fluor 594 (red) comes from the right. Middle traces, Slow outward inhibitory currents locked to the respiration rhythm (resp) dominated the spontaneous activity of this cell at $V_{\mathrm{h}}=0 \mathrm{mV}$ (top), whereas slow inward excitatory currents dominated the activity at $V_{\mathrm{h}}=-80 \mathrm{mV}$ (bottom). Right, Fifty consecutive respiratory cycles with their correlated currents are superimposed. Black traces are the average.

suggest that $\mathrm{EYFP}^{+}$PG cells faithfully follow the activity of mitral and tufted cells that also fired bursts of action potentials at each respiration cycle (data not shown) as shown previously (Luo and Katz, 2001; Margrie and Schaefer, 2003). Therefore, intraglomerular lateral inhibition should be activated at each sniff and compete with the depolarization that generates the firing of principal neurons (Luo and Katz, 2001; Margrie and Schaefer, 2003). We tested this hypothesis in voltage-clamped tufted rather than mitral cells that are localized deeper in the brain and more difficult to voltage clamp. As expected, rhythmic slow IPSCs (halfwidth, $88 \pm 22 \mathrm{~ms} ; n=7$ ) correlated with the respiration were recorded at the reversal potential for excitation $\left(V_{\mathrm{h}}=10 / 0 \mathrm{mV}\right)$. As illustrated in Figure $6 B$, in cells in which EPSCs and IPSCs were recorded successively, IPSCs occurred at the same frequency and at the same phase of the respiration cycle as EPSCs $(n=5)$. Therefore, these data indicate that circuits mediating intraglomerular lateral inhibition operate in vivo in the absence of exogenous odorants at each respiration and thus likely provide a rhythmic inhibition that competes with the excitation of mitral and tufted cells.

ON-evoked inhibition is generated within the glomerulus and involves $\mathrm{EYFP}^{+}$PG cells

In slices, stimulation of OSNs evokes a prominent barrage of summating discrete IPSCs in mitral and tufted cells (Najac et al., 2011). A recent study suggests that intraglomerular circuits mediate the early part of this OSN-evoked inhibition (Shao et al., 2012). Consistent with this study, the early component of the composite ON-evoked IPSC persisted in the presence D-AP-5 and CPCCOEt (onset latency, $7.9 \pm 2.1 \mathrm{~ms}$; half-width, $61.6 \pm$ $29.6 \mathrm{~ms} ; n=6$ mitral cells; Fig. 7A) and was fully blocked when GBZ was applied locally, either continuously (Fig. 7D) or transiently (Fig. 7E), inside the glomerulus. In both cases, spontaneous IPSCs were not blocked. ON stimulation evoked a similar inhibition in tufted cells (onset latency, $6.7 \pm 1.0 \mathrm{~ms}$; half-width, $52.7 \pm 29.3 \mathrm{~ms} ; n=7$ ) and ET cells (onset latency, $6.4 \pm 1.3 \mathrm{~ms}$; 
A

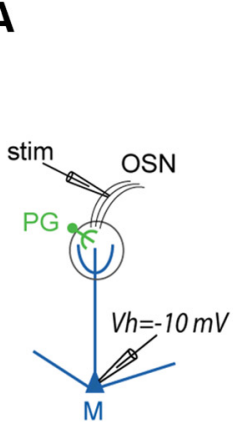

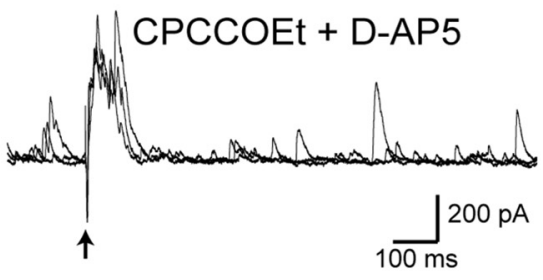

C

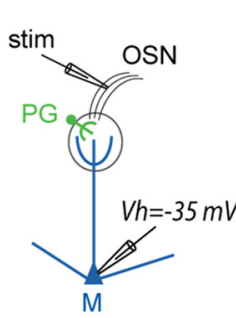

control

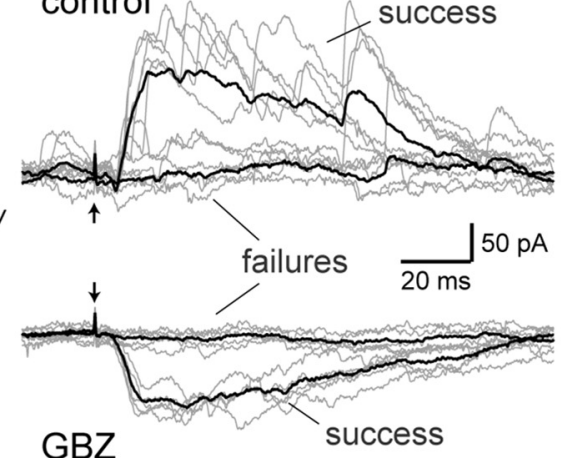

E

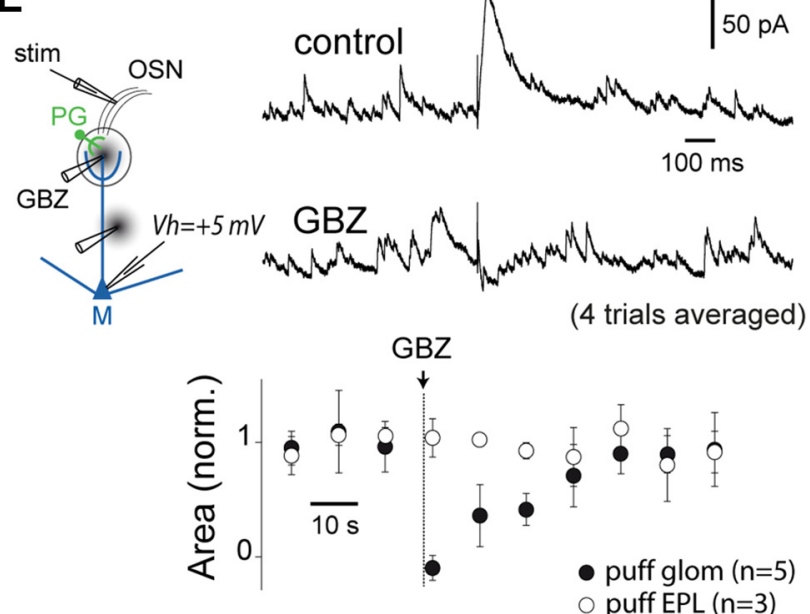

B

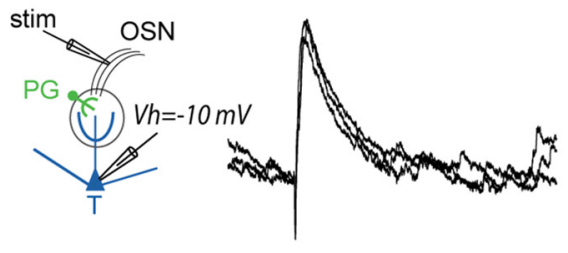

half width (ms)
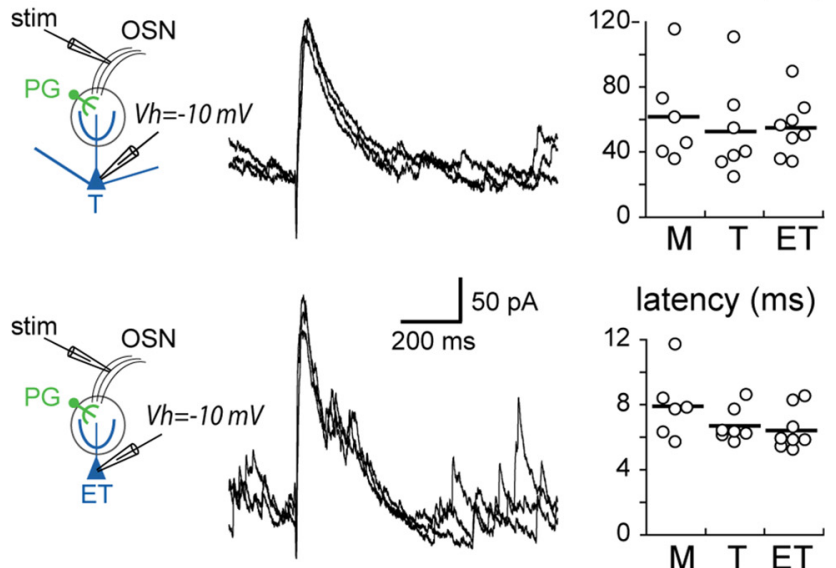

latency (ms)

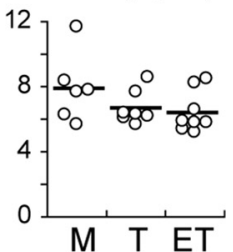

D
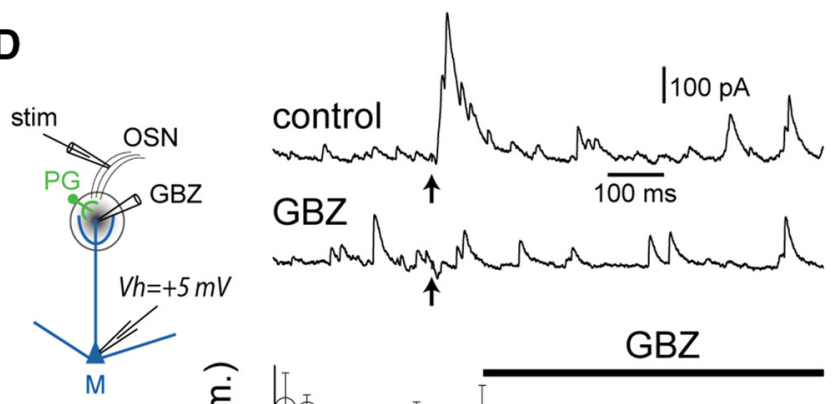
GBZ GBZ

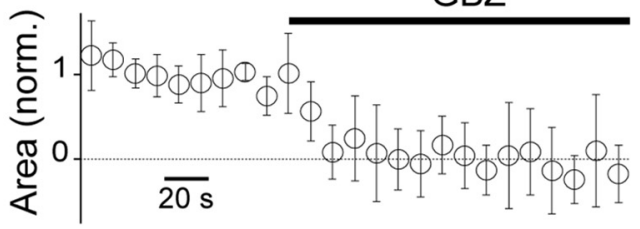

F
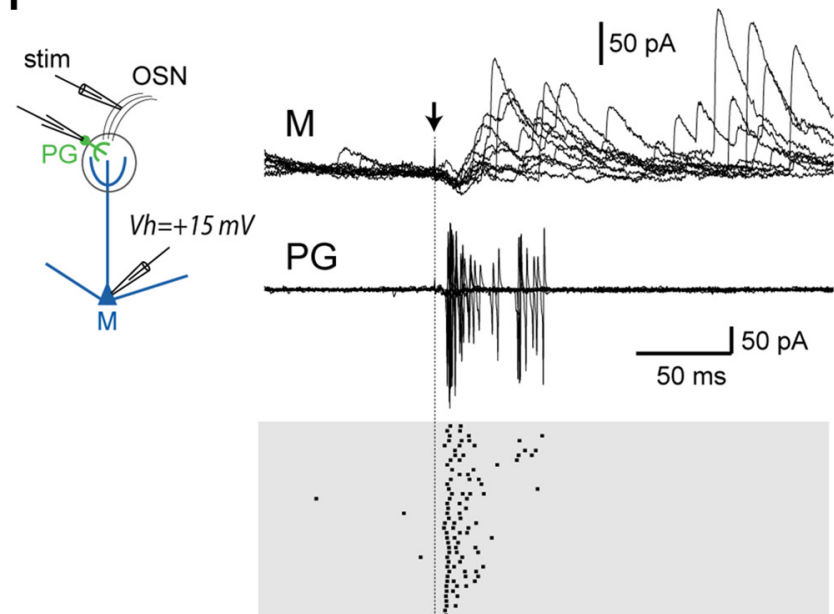

Figure 7. EYFP ${ }^{+} \mathrm{PG}$ cells mediate OSN-evoked feedforward inhibition. $A$, Mitral cell (M) responses evoked by a stimulation of OSNs in control conditions (top) and in the presence of CPCCOEt (100 $\mu \mathrm{M})$ and D-AP-5 (50 $\mu \mathrm{m}$; bottom). Individual traces recorded at $V_{\mathrm{h}}=-10 \mathrm{mV}$ are superimposed. $B, 0 \mathrm{~N}$-evoked feedforward inhibition in a tufted cell (T, top) and in an ET cell (bottom). Individual traces recorded at $V_{\mathrm{h}}=-10 \mathrm{mV}$ in the presence of CPCCOEt $(100 \mu \mathrm{M})$ and D-AP-5 $(50 \mu \mathrm{M})$ are superimposed. Right, Summary plots comparing the half-width and latency of the ISPC in mitral, tufted, and ET cells. Horizontal bars are the average. $C$, Mitral cell responses evoked by minimal stimulation of OSNs that evoked a response (success) in $\sim 50 \%$ of the trials in the presence of CPCCOEt plus D-AP-5 before (top, control) and after (bottom, $4 \mu \mathrm{M}$ ) bath application of GBZ. Individual traces recorded at $V_{\mathrm{h}}=-35 \mathrm{mV}$ are superimposed in gray. Average responses are shown in black. $\boldsymbol{D}$, ON-evoked mitral cell responses in the presence of CPCCOEt plus D-AP-5 (top) and during local perfusion of GBZ (25 $\mu \mathrm{M})$ inside the glomerulus to which the recorded mitral cell projected (middle trace). Single traces recorded at $V_{h}=5 \mathrm{mV}$. Note that intraglomerular perfusion of GBZ did not block spontaneous IPSCs. Bottom, Normalized area of the evoked IPSCs (measured during the first 100 $\mathrm{ms}$ ) over time during local perfusion of GBZ within the glomerulus. Average from seven cells ( 5 mitral and 2 tufted cells). E, Same as in D, but GBZ was applied transiently (50 $\mu \mathrm{m}, 150 \mathrm{~ms}$ ). Bottom,

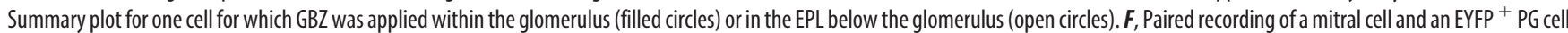
projecting into the same glomerulus. The mitral cell was recorded in the whole-cell mode $\left(V_{h}=15 \mathrm{mV}\right)$, whereas the $P G$ cell was recorded in loose cell-attached mode. A minimal stimulation (18 $\mu \mathrm{A}$ ) was used to stimulate OSNs in the presence of CPCCOEt plus D-AP-5. IPSCs in the mitral cell (top) were correlated with action potentials in the PG cell (middle). Bottom, Raster plot of every successful trial in the PG cell. 
half-width, $54.9 \pm 17.8 \mathrm{~ms} ; n=8$; no statistical difference with values in mitral cells; Fig. $7 B$ ). Together, D-AP-5 and CPCCOEt shorten the excitation of mitral and tufted cells (De Saint Jan and Westbrook, 2007) and, consequently, the excitatory drive of interneurons. In addition, the NMDA receptor antagonist limits GABA release from granule cells (Isaacson and Strowbridge, 1998; Schoppa et al., 1998). Because IPSCs were evoked even when OSNs were stimulated with minimal intensities $(25-50 \mu \mathrm{A}$, $n=10$ mitral cells; Fig. $7 C$ ), interneurons that mediate this inhibition should be activated by weak ON inputs. Do EYFP ${ }^{+} \mathrm{PG}$ cells participate in ON-evoked inhibition? To investigate this possibility, we recorded IPSCs in a mitral cell while monitoring the activity of an EYFP ${ }^{+}$PG cell in the loose cell-attached mode under conditions of minimal stimulation that recruit only a fraction of PG cells but activate inhibition. Under these conditions and in the presence of D-AP-5 and CPCCOEt, EYFP $^{+}$PG cells fired $2.4 \pm 0.9$ action potentials $(n=4$ pairs) in $95 \pm 5 \%$ of the trials in which a compound IPSC was evoked in the mitral cell (Fig. 7F). Together, these results suggest that glomerular circuits mediate the early phase of ON-evoked inhibition and that $\mathrm{EYFP}^{+} \mathrm{PG}$ cells contribute to this inhibition.

\section{Glomerular inhibition promotes spike timing variability in mitral cells}

A single stimulation of OSNs evokes polysynaptic EPSCs and IPSCs in mitral and tufted cells (Najac et al., 2011). Whereas the excitation is almost identical from trial to trial, the inhibition is composed of asynchronous discrete IPSCs with variable timing. To assess the influence of intraglomerular inhibition on the spike output of principal cells, we made loose cell-attached recordings in mitral cells and compared their ON-evoked discharge under control conditions and when intraglomerular inhibition was blocked by a local application of GBZ within the glomerulus ( $n=$ 9; Fig. 8). In some experiments $(n=3)$, we simultaneously monitored evoked IPSCs in a second cell projecting into the same glomerulus to better control the stimulation and the effect of GBZ, as in the example shown in Figure 8, $B$ and $C$. Mitral cells responded to the stimulation with a long-lasting barrage of spikes that returned to baseline frequency after a double-exponential decay $(25.3 \pm 31.4$ and $369 \pm 184 \mathrm{~ms})$. Intraglomerular application of GBZ increased firing rate $(32 \pm 26 \%$ increase compared with control during the $3 \mathrm{~s}$ after the stimulus, $p=0.006$ ), especially during the first $200 \mathrm{~ms}$ after the stimulus (Fig. 8 B, C). Furthermore, spike rasters of individual neurons suggest that spike time tended to be more reliable in the presence of GBZ (Fig. 8C). To quantify the effect of intraglomerular inhibition on spike timing, we ranked the interspike intervals (ISIs) in each trial for each mitral cell. We compared the distribution of their duration across trials in the presence and absence of GBZ in a short time window (200 ms) after ON stimulation (Fig. 8D). Most ISIs after the stimulus were significantly different in the two conditions for nearly all neurons (two-sampled Kolmogorov-Smirnov test, $p \leq$ $6.15 \times 10^{-4}$; Fig. $8 E$ ). However, these differences in the ISI duration distributions could result from both increased firing rates and increased spike reliability in the presence of GBZ. Therefore, we estimated the coefficient of variation $\left(\mathrm{CV}_{\text {ISI }}\right)$ of each ISI across trials in the two conditions (Fig. $8 F$ ). We found that the $\mathrm{CV}$ of the first two ISIs after the stimulus onset were significantly smaller in the presence of GBZ (first ISI: $\mathrm{CV}_{\text {ISI }}{ }^{\mathrm{GBZ}}=0.11 \pm 0.06$, $\mathrm{CV}_{\text {ISI }}{ }^{\mathrm{CNT}}=0.52 \pm 0.35, p \leq 0.01$; second ISI: $\mathrm{CV}_{\text {ISI }}{ }^{\mathrm{GBZ}}=0.18 \pm$ $\left.0.14, \mathrm{CV}_{\text {ISI }}{ }^{\mathrm{CNT}}=0.44 \pm 0.26, p \leq 0.01\right)$. Subsequent ISIs did not show any significant differences in CV across trials. Thus, intraglomerular inhibition not only reduces spike frequency but also promotes trial-to-trial spike timing variability within a short time window after $\mathrm{ON}$ stimulation. To understand how intraglomerular lateral inhibition could affect the response of an ensemble of cells that receive a simultaneous $\mathrm{ON}$ input, we then simulated an ensemble of nine mitral cells by pooling the data from our individual recordings. For every ensemble response, we calculated the $\mathrm{CV}$ of ISIs across the nine mitral cells in the presence and absence of GBZ (Fig. 8G). We found that the CV of the first two ISIs after the stimulus onset were significantly larger in the control condition than in the presence of GBZ (first ISI: $\mathrm{CV}_{\mathrm{ISI}}{ }^{\mathrm{GBZ}}=0.36 \pm$ $0.08, \mathrm{CV}_{\text {ISI }}{ }^{\mathrm{CNT}}=1.04 \pm 0.20, p \leq 0.001$; second ISI: $\mathrm{CV}_{\text {ISI }}{ }^{\mathrm{GBZ}}=$ $\left.0.24 \pm 0.08, \mathrm{CV}_{\text {ISI }}{ }^{\mathrm{CNT}}=0.61 \pm 0.21, p \leq 0.001\right)$. This increase in cell-to-cell spike redundancy in GBZ was restricted to the first few spikes after ON stimulation as for the trial-to-trial reliability described above for each cell.

Thus, intraglomerular inhibition counteracts membrane properties and dendrodendritic electrical and synaptic interactions that constrain mitral cells to fire reliable and precisely timed action potentials in response to a stereotyped excitatory input, thereby reducing the similarity of the discharge of each cell.

\section{Discussion}

We characterized a specific population of PG cells that mediates lateral inhibition between olfactory bulb principal neurons projecting into the same glomerulus. This intraglomerular inhibitory pathway is recruited by even the weakest ON input and shapes the spike output of mitral and tufted cells. Moreover, in vivo recordings show that intraglomerular lateral inhibition is activated at each respiration cycle.

We took advantage of a transgenic mouse expressing EYFP in a subset of PG cells to characterize the properties of an intraglomerular inhibitory circuit that modulates the spike output of principal neurons. $\mathrm{EYFP}^{+} \mathrm{PG}$ cells include, although not exclusively, cells expressing $\mathrm{CB}$ but does not overlap with the two other well identified populations of PG cells immunoreactive for CR and $\mathrm{TH}$. Electron microscopy studies of $\mathrm{CB}^{+} \mathrm{PG}$ cells have shown that they receive synapses from mitral/tufted cells but rarely from OSNs (Toida et al., 1998; Kosaka and Kosaka, 2007; Panzanelli et al., 2007). Moreover, ultrastructural evidence suggests that $\mathrm{CB}^{+} \mathrm{PG}$ cells do not have an axon and release their neurotransmitter from dendrites within their glomerulus (Kosaka and Kosaka, 2010). Our functional and morphological characterization of $\mathrm{EYFP}^{+} \mathrm{PG}$ cells is consistent with these data. We have demonstrated that mitral, tufted, and ET cells make excitatory synapses on $\mathrm{EYFP}^{+} \mathrm{PG}$ cells. Thus, $\mathrm{EYFP}^{+} \mathrm{PG}$ cells responded to a stimulation of OSNs with a short barrage of EPSCs that lasted only few tens of milliseconds. Similar responses were observed in a subgroup of $\mathrm{EYFP}^{-} \mathrm{PG}$ cells, suggesting that EYFP $^{+}$PG cells, although they constitute $30 \%$ of PG cells, might be representative of an even larger group of type 2 PG cells with similar excitatory connections. The transient nature of this response, which contrasts with the long-lasting responses observed in other PG cells, was remarkably consistent despite the diversity of immunohistochemical profiles and membrane properties among $\mathrm{EYFP}^{+} \mathrm{PG}$ cells. The onset latency of the response was quite fast $(\sim 3 \mathrm{~ms}$ ) yet longer and more variable than in ET or PG cells connected directly to OSNs, suggesting that EYFP ${ }^{+} \mathrm{PG}$ cells do not receive direct inputs from OSNs. This fast-onset polysynaptic activation likely relies on ET cells that fire as early as $2 \mathrm{~ms}$ after the stimulation of OSNs (De Saint Jan et al., 2009) and elicit an $\mathrm{EPSC}$ in $\mathrm{EYFP}^{+} \mathrm{PG}$ cells in $\sim 1 \mathrm{~ms}$.

Some PG cells are activated by weak ON inputs (Gire and Schoppa, 2009) or the firing of a single principal cell (Murphy et 


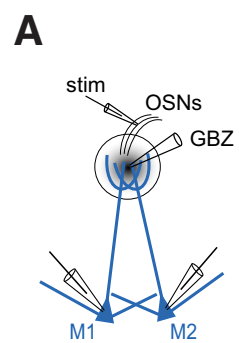

B
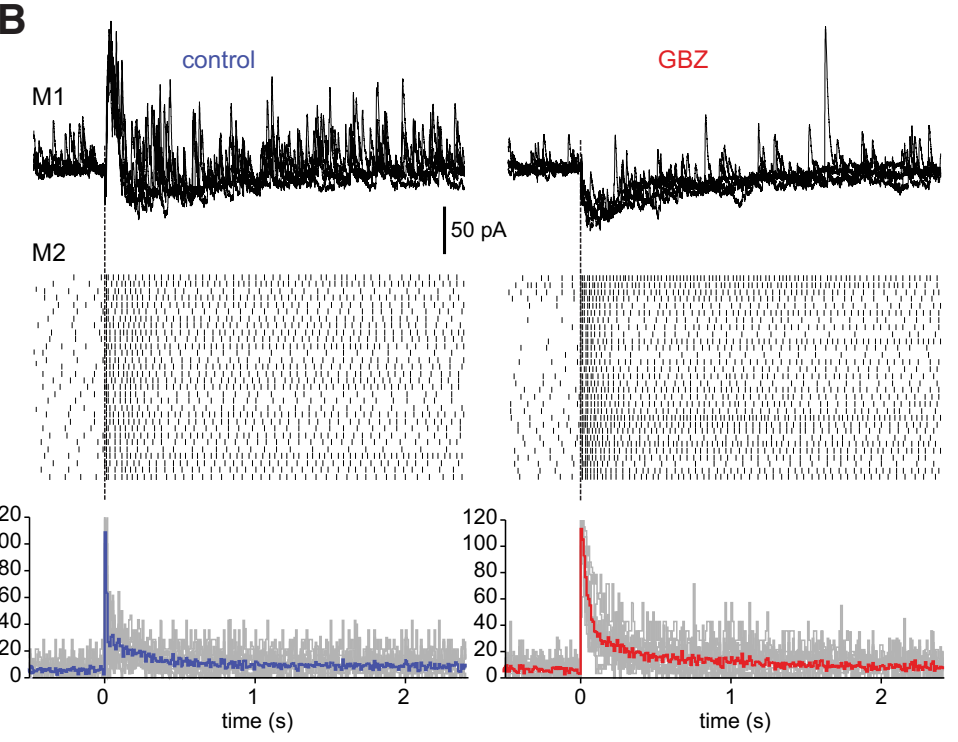

C
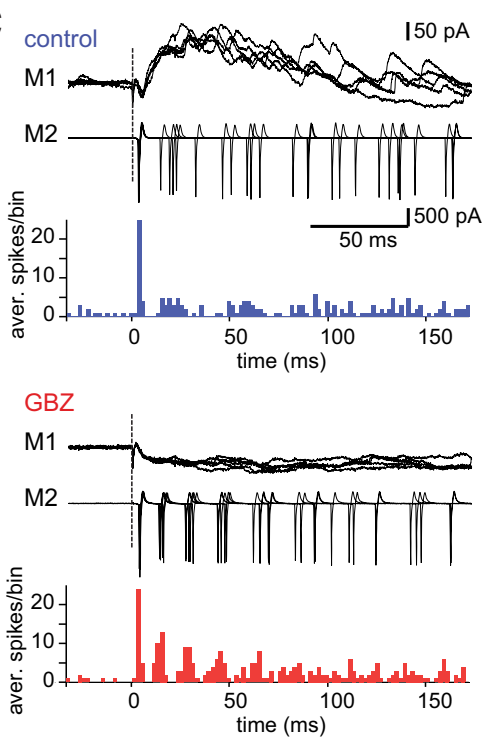

D

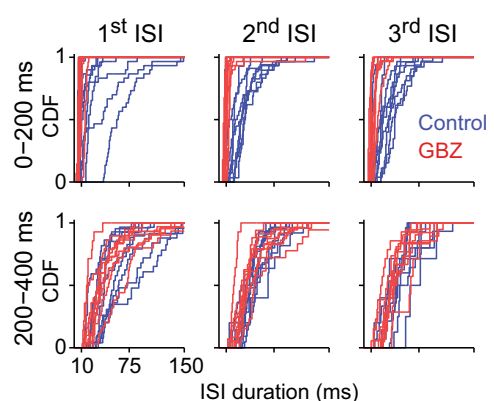

E

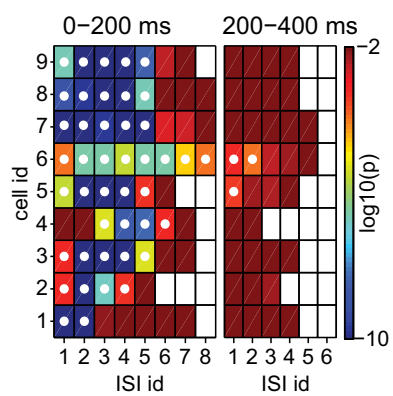

$\mathbf{F}$

trial-to-trial variability

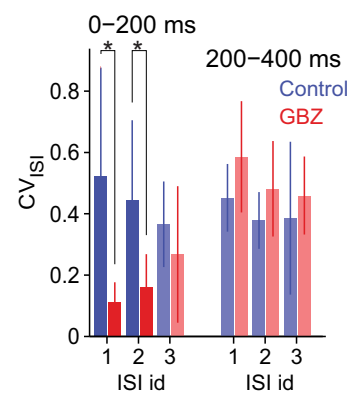

G

G cell-to-cell variability

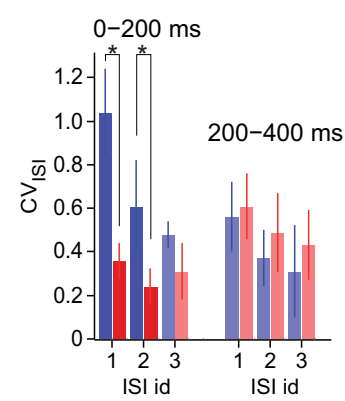

Figure 8. Intraglomerular inhibition reduces output frequency and spike timing redundancy in mitral cells. $\boldsymbol{A}$, Schematic of the experiment. $\boldsymbol{B}$, Paired recording of 0N-evoked responses in two mitral cells (M1 and M2) projecting into the same glomerulus. M1 (top traces) was recorded in whole-cell mode at $V_{\mathrm{h}}=5 \mathrm{mV}$. Five responses are superimposed under control conditions (left) and during local perfusion of GBZ $(25 \mu \mathrm{m}$ ) within the glomerulus (right). Middle, Raster plots of the firing of M2 recorded simultaneously in loose cell-attached mode. The dashed line indicates the stimulation $(25 \mu \mathrm{A})$ time. Bottom, Mean firing rate across nine mitral cells recorded in cell-attached mode in control conditions (left, blue) and in the presence of GBZ (right, red). Thick traces are grand averages, and gray traces are averages for each cell. Bin width, $10 \mathrm{~ms}$. C, Zoom on the initial phase of the responses shown in $B$. Bottom, PSTH for the same M2 cell in control conditions (top) and in the presence of GBZ (bottom). Bin width, $2 \mathrm{~ms}$. D, Top, Cumulative density function (CDF) of the first three ISIs (first 4 spikes) in the $0-200$ ms time window for nine mitral cells recorded in cell-attached mode. Blue colors correspond to the control data, and red colors indicate GBZ application. The three ISIs are shown in different columns. Bottom, Same as the top for the $200-400 \mathrm{~ms}$ time window. E, Significance testing of the difference between ISI distribution in control conditions and in the presence of GBZ. Two-sampled Kolmogorov-Smirnov test $p$ values are shown in log scale. Null hypothesis is that the ISI distribution in control conditions and in the presence of GBZ are the same. $x$-Axis refers to the ISI, and the $y$-axis refers to the cell number. $p$ values are higher within the $0-200 \mathrm{~ms}$ than in the $200-400 \mathrm{~ms}$ time period. Significantly different ISIs in control and GBZ are marked with a white dot ( $\alpha$ values $=0.001, n=9$ mitral cells). $\boldsymbol{F}$, In the presence of GBZ, the first two ISIs after stimulation become highly reliable across trials. $\mathrm{CV}_{\mathrm{ISI}}$ of the first three ISIs. In $\boldsymbol{F}$ and $\boldsymbol{G}$, each bar shows the mean $\pm S D$ of $\mathrm{CV}_{\mid \mathrm{ISI}}$ in control conditions (blue) and in the presence of GBZ (red) for the first three ISIs within the $0-200$ and $200-400$ ms time windows. $G$, In the presence of GBZ, in each trial, the first two ISIs after stimulation become highly reliable across cells in a simulated ensemble of nine mitral cells ( $n=14$ random trials).

al., 2005). Current models suggest that low-threshold intraglomerular inhibition may serve as a gatekeeper that shunts weak ON inputs (Gire and Schoppa, 2009) and may separate the firing phase of the two output channels (tufted vs mitral cells) along a respiration cycle (Fukunaga et al., 2012). Our results show that $\mathrm{EYFP}^{+} \mathrm{PG}$ cells constitute a large fraction of these highly excitable PG cells that also include a minority of EYFP ${ }^{-}$PG cells. We have demonstrated that they mediate a form of lateral inhibition, the firing of a single principal neuron producing disynaptic inhibition of other mitral and tufted cells within the same glomerulus. This recurrent pathway is recruited by even the weakest $\mathrm{ON}$ input and mediates ON-evoked inhibition of principal neurons. We also found that $\mathrm{EYFP}^{+} \mathrm{PG}$ cells indiscriminately release GABA onto mitral, tufted, and ET cells and that ON-evoked intraglomerular inhibition has a similar time course in these three types of neurons. Our experimental results do not support a re- cent study that stated that, unlike mitral cells, tufted cells are not, or are less, modulated by intraglomerular inhibition (Fukunaga et al., 2012). However, that study relied on a theoretical network model based on experimentally undemonstrated differences in PG cell inputs on mitral and tufted cells. More recently, Burton and Urban (2014) suggested that the different firing phases of mitral and tufted cells may be attributable to a greater intrinsic excitability and a stronger afferent-evoked excitation in tufted cells.

Evaluating the contribution of $\mathrm{EYFP}^{+} \mathrm{PG}$ cells in $\mathrm{ON}$-evoked inhibition would require their selective manipulation, for instance, with optogenetics. However, to date, there is no selective marker for this population, which impedes its genetic manipulation. Nevertheless, our data suggest that only a minority of PG cells have a similar activation threshold than $\mathrm{EYFP}^{+}$PG cells and potentially contribute to ON-evoked inhibition. Moreover, we 
show that half of $\mathrm{CR}^{+} \mathrm{PG}$ cells are not, or are only weakly, activated by $\mathrm{ON}$ inputs and thus unlikely to participate. However, $\mathrm{ON}$-evoked inhibition lasts longer than the firing of EYFP ${ }^{+} \mathrm{PG}$ cells, suggesting that other PG cell subtypes that respond to an ON input with a longer firing may generate late IPSCs. Do granule or $\mathrm{PV}^{+}$cells also contribute to the early phase of ON-evoked inhibition? Several results argue against this idea. As shown previously (Shao et al., 2012), early IPSCs persisted in the presence of NMDA receptor blockers that limit the activation of granule cells (Isaacson and Strowbridge, 1998; Schoppa et al., 1998). Second, ON-evoked inhibition was abolished by intraglomerular perfusion of GBZ, suggesting that $\mathrm{PV}^{+}$and granule cells that do not make synapses within the glomerulus do not contribute. Consistent with this conclusion, the time course of ON-evoked inhibition was similar in ET cells that presumably do not interact with granule cells and $\mathrm{PV}^{+}$interneurons. This indicates that intraglomerular pathways are sufficient to produce a strong inhibition. Finally, granule cells respond to a glomerular stimulation with an $\sim 70$ ms delayed firing (Schoppa and Westbrook, 1999; Kapoor and Urban, 2006) that does not match with the early onset of OSN-evoked inhibition $(\sim 6 \mathrm{~ms})$.

The short timescale of $\mathrm{EYFP}^{+} \mathrm{PG}$ cell-mediated intraglomerular inhibition in slices $(\sim 100 \mathrm{~ms})$ is physiologically relevant for odor processing. In vivo, spontaneous firing and odor-evoked discharges of mitral and tufted cells are often constrained by the $\sim 2-10 \mathrm{~Hz}$ respiratory rhythm. Thus, mitral and tufted cells fire action potentials during a brief $(50-150 \mathrm{~ms})$ phase of the respiration cycle (Cang and Isaacson, 2003; Margrie and Schaefer, 2003; Davison and Katz, 2007; Dhawale et al., 2010). As reported previously (Luo and Katz, 2001; Margrie and Schaefer, 2003), rhythmic depolarizations locked to the respiration underlie this activity. We have found that these EPSPs compete with IPSPs in anesthetized mice. Because $\mathrm{EYFP}^{+}$PG cells fire action potentials at each respiration cycle, they likely mediate at least a fraction of this inhibition. Similar to $\mathrm{EYFP}^{+} \mathrm{PG}$ cells, $\mathrm{PV}^{+}$cells are highly active in vivo, even in the absence of exogenously applied odorants (Miyamichi et al., 2013), and thus may contribute to this inhibition. In contrast, granule cells have a low spontaneous firing rate in anesthetized mice (Cang and Isaacson, 2003; Margrie and Schaefer, 2003; Kato et al., 2012). However, their activity is strongly enhanced in the awake animal, suggesting that the influence of each interneuron population may differ in the awake and anesthetized state (Kato et al., 2012).

In classical pathways, feedforward inhibition quickly follows monosynaptic excitation and defines a short temporal window of opportunity for the postsynaptic neuron to fire. Thus, inhibition often promotes spike timing precision (Pouille and Scanziani, 2001). In contrast, we found that ON-evoked intraglomerular inhibition promotes spike timing variability in olfactory bulb mitral cells from trial to trial and also from cell to cell. Intraglomerular lateral inhibition relies on synapses with low release probability, whereas the long-lasting ON-evoked excitation of mitral and tufted cells relies on excitatory synapses with high release probability (Najac et al., 2011). Therefore, IPSC timing and amplitudes vary from trial to trial and from cell to cell, unlike excitation that is highly reproducible. Moreover, membrane properties constrain mitral cells to fire reliable and precisely timed action potentials across trials in response to an identical synaptic-like fluctuating stimulus (Padmanabhan and Urban, 2010) or an EPSP waveform (Balu et al., 2004). This explains why each mitral cell responded to the afferent input with a stereotyped pattern of spikes in the presence of GBZ. In addition, intraglomerular dendrodendritic excitatory interactions and gap-junction coupling drive synchronous firing in principal cells connected to the same glomerulus (Schoppa and Westbrook, 2002; Ma and Lowe, 2010). Thus, intraglomerular inhibition competes with multiple mechanisms that tend to synchronize the output of a glomerulus. Many neurons of the olfactory bulb network fire in synchrony in the presence of an odorant, suggesting that olfactory coding in the olfactory bulb relies, at least in part, on precise spike timing in a population of cells (Bathellier et al., 2010). Although the functional implication of intraglomerular inhibition is at present uncertain, one possible function of this pathway may be to prevent correlated spiking in the absence of exogenous odorants.

\section{References}

Abraham NM, Egger V, Shimshek DR, Renden R, Fukunaga I, Sprengel R, Seeburg PH, Klugmann M, Margrie TW, Schaefer AT, Kuner T (2010) Synaptic inhibition in the olfactory bulb accelerates odor discrimination in mice. Neuron 65:399-411. CrossRef Medline

Balu R, Larimer P, Strowbridge BW (2004) Phasic stimuli evoke precisely timed spikes in intermittently discharging mitral cells. J Neurophysiol 92:743-753. CrossRef Medline

Bathellier B, Gschwend O, Carleton A (2010) Temporal coding in olfaction. In: The neurobiology of olfaction (Menini A, ed), pp 329-348. Boca Raton, FL: CRC.

Burton SD, Urban NN (2014) Greater excitability and firing irregularity of tufted cells underlies distinct afferent-evoked activity of olfactory bulb mitral and tufted cells. J Physiol 592:2097-2118. CrossRef Medline

Cang J, Isaacson JS (2003) In vivo whole-cell recording of odor-evoked synaptic transmission in the rat olfactory bulb. J Neurosci 23:4108-4116. Medline

Caputi A, Rozov A, Blatow M, Monyer H (2009) Two calretinin-positive GABAergic cell types in layer $2 / 3$ of the mouse neocortex provide different forms of inhibition. Cereb Cortex 19:1345-1359. CrossRef Medline

Charpak S, Mertz J, Beaurepaire E, Moreaux L, Delaney K (2001) Odorevoked calcium signals in dendrites of rat mitral cells. Proc Natl Acad Sci U S A 98:1230-1234. CrossRef Medline

Christie JM, Schoppa NE, Westbrook GL (2001) Tufted cell dendrodendritic inhibition in the olfactory bulb is dependent on NMDA receptor activity. J Neurophysiol 85:169-173. Medline

Davison IG, Katz LC (2007) Sparse and selective odor coding by mitral/ tufted neurons in the main olfactory bulb. J Neurosci 27:2091-2101. CrossRef Medline

De Saint Jan D, Westbrook GL (2007) Disynaptic amplification of metabotropic glutamate receptor 1 responses in the olfactory bulb. J Neurosci 27:132-140. CrossRef Medline

De Saint Jan D, Hirnet D, Westbrook GL, Charpak S (2009) External tufted cells drive the output of olfactory bulb glomeruli. J Neurosci 29:20432052. CrossRef Medline

Dhawale AK, Hagiwara A, Bhalla US, Murthy VN, Albeanu DF (2010) Nonredundant odor coding by sister mitral cells revealed by light addressable glomeruli in the mouse. Nat Neurosci 13:1404-1412. CrossRef Medline

Dong HW, Hayar A, Ennis M (2007) Activation of group I metabotropic glutamate receptors on main olfactory bulb granule cells and periglomerular cells enhances synaptic inhibition of mitral cells. J Neurosci 27: 5654-5663. CrossRef Medline

Fukunaga I, Berning M, Kollo M, Schmaltz A, Schaefer AT (2012) Two distinct channels of olfactory bulb output. Neuron 75:320-329. CrossRef Medline

Gire DH, Schoppa NE (2009) Control of on/off glomerular signaling by a local GABAergic microcircuit in the olfactory bulb. J Neurosci 29:1345413464. CrossRef Medline

Hayar A, Karnup S, Ennis M, Shipley MT (2004) External tufted cells: a major excitatory element that coordinates glomerular activity. J Neurosci 24:6676-6685. CrossRef Medline

Isaacson JS, Strowbridge BW (1998) Olfactory reciprocal synapses: dendritic signaling in the CNS. Neuron 20:749-761. CrossRef Medline

Kapoor V, Urban NN (2006) Glomerulus-specific, long-latency activity in the olfactory bulb granule cell network. J Neurosci 26:11709-11719. CrossRef Medline

Kato HK, Chu MW, Isaacson JS, Komiyama T (2012) Dynamic sensory 
representations in the olfactory bulb: modulation by wakefulness and experience. Neuron 76:962-975. CrossRef Medline

Kato HK, Gillet SN, Peters AJ, Isaacson JS, Komiyama T (2013) Parvalbumin-expressing interneurons linearly control olfactory bulb output. Neuron 80:1218-1231. CrossRef Medline

Kiyokage E, Pan YZ, Shao Z, Kobayashi K, Szabo G, Yanagawa Y, Obata K, Okano H, Toida K, Puche AC, Shipley MT (2010) Molecular identity of periglomerular and short axon cells. J Neurosci 30:1185-1196. CrossRef Medline

Kosaka K, Kosaka T (2007) Chemical properties of type 1 and type 2 periglomerular cells in the mouse olfactory bulb are different from those in the rat olfactory bulb. Brain Res 1167:42-55. CrossRef Medline

Kosaka T, Kosaka K (2010) Heterogeneity of calbindin-containing neurons in the mouse main olfactory bulb: I. General description. Neurosci Res 67:275-292. CrossRef Medline

Luo M, Katz LC (2001) Response correlation maps of neurons in the mammalian olfactory bulb. Neuron 32:1165-1179. CrossRef Medline

Ma J, Lowe G (2010) Correlated firing in tufted cells of mouse olfactory bulb. Neuroscience 169:1715-1738. CrossRef Medline

Margrie TW, Schaefer AT (2003) Theta oscillation coupled spike latencies yield computational vigour in a mammalian sensory system. J Physiol 546:363-374. CrossRef Medline

Margrie TW, Meyer AH, Caputi A, Monyer H, Hasan MT, Schaefer AT, Denk W, Brecht M (2003) Targeted whole-cell recordings in the mammalian brain in vivo. Neuron 39:911-918. CrossRef Medline

McQuiston AR, Katz LC (2001) Electrophysiology of interneurons in the glomerular layer of the rat olfactory bulb. J Neurophysiol 86:1899-1907. Medline

Metzger F, Repunte-Canonigo V, Matsushita S, Akemann W, Diez-Garcia J, Ho CS, Iwasato T, Grandes P, Itohara S, Joho RH, Knöpfel T (2002) Transgenic mice expressing a $\mathrm{pH}$ and $\mathrm{Cl}^{-}$sensing yellow-fluorescent protein under the control of a potassium channel promoter. Eur J Neurosci 15:40-50. CrossRef Medline

Miyamichi K, Shlomai-Fuchs Y, Shu M, Weissbourd BC, Luo L, Mizrahi A (2013) Dissecting local circuits: parvalbumin interneurons underlie broad feedback control of olfactory bulb output. Neuron 80:1232-1245. CrossRef Medline

Mori K, Nagao H, Yoshihara Y (1999) The olfactory bulb: coding and processing of odor molecule information. Science 286:711-715. CrossRef Medline

Murphy GJ, Darcy DP, Isaacson JS (2005) Intraglomerular inhibition: signaling mechanisms of an olfactory microcircuit. Nat Neurosci 8:354-364. CrossRef Medline

Najac M, De Saint Jan D, Reguero L, Grandes P, Charpak S (2011) Monosynaptic and polysynaptic feed-forward inputs to mitral cells from olfactory sensory neurons. J Neurosci 31:8722-8729. CrossRef Medline
Padmanabhan K, Urban NN (2010) Intrinsic biophysical diversity decorrelates neuronal firing while increasing information content. Nat Neurosci 13:1276-1282. CrossRef Medline

Panzanelli P, Fritschy JM, Yanagawa Y, Obata K, Sassoè-Pognetto M (2007) GABAergic phenotype of periglomerular cells in the rodent olfactory bulb. J Comp Neurol 502:990-1002. CrossRef Medline

Parrish-Aungst S, Shipley MT, Erdelyi F, Szabo G, Puche AC (2007) Quantitative analysis of neuronal diversity in the mouse olfactory bulb. J Comp Neurol 501:825-836. CrossRef Medline

Pinching AJ, Powell TP (1971a) The neuropil of the glomeruli of the olfactory bulb. J Cell Sci 9:347-377. Medline

Pinching AJ, Powell TP (1971b) The neuron types of the glomerular layer of the olfactory bulb. J Cell Sci 9:305-345. Medline

Pouille F, Scanziani M (2001) Enforcement of temporal fidelity in pyramidal cells by somatic feed-forward inhibition. Science 293:1159-1163. CrossRef Medline

Schoppa NE, Westbrook GL (1999) Regulation of synaptic timing in the olfactory bulb by an A-type potassium current. Nat Neurosci 2:11061113. CrossRef Medline

Schoppa NE, Westbrook GL (2002) AMPA autoreceptors drive correlated spiking in olfactory bulb glomeruli. Nat Neurosci 5:1194-1202. CrossRef Medline

Schoppa NE, Kinzie JM, Sahara Y, Segerson TP, Westbrook GL (1998) Dendrodendritic inhibition in the olfactory bulb is driven by NMDA receptors. J Neurosci 18:6790-6802. Medline

Shao Z, Puche AC, Kiyokage E, Szabo G, Shipley MT (2009) Two GABAergic intraglomerular circuits differentially regulate tonic and phasic presynaptic inhibition of olfactory nerve terminals. J Neurophysiol 101: 1988-2001. CrossRef Medline

Shao Z, Puche AC, Liu S, Shipley MT (2012) Intraglomerular inhibition shapes the strength and temporal structure of glomerular output. J Neurophysiol 108:782-793. CrossRef Medline

Shepherd GM (2004) The synaptic organization of the brain, Ed 5. Oxford, UK: Oxford UP.

Toida K, Kosaka K, Heizmann CW, Kosaka T (1998) Chemically defined neuron groups and their subpopulations in the glomerular layer of the rat main olfactory bulb: III. Structural features of calbindin D28K-immunoreactive neurons. J Comp Neurol 392:179-198. CrossRef Medline

Urban NN, Sakmann B (2002) Reciprocal intraglomerular excitation and intra- and interglomerular lateral inhibition between mouse olfactory bulb mitral cells. J Physiol 542:355-367. CrossRef Medline

Whitman MC, Greer CA (2007) Adult-generated neurons exhibit diverse developmental fates. Dev Neurobiol 67:1079-1093. CrossRef Medline

Yokoi M, Mori K, Nakanishi S (1995) Refinement of odor molecule tuning by dendrodendritic synaptic inhibition in the olfactory bulb. Proc Natl Acad Sci U S A 92:3371-3375. CrossRef Medline 